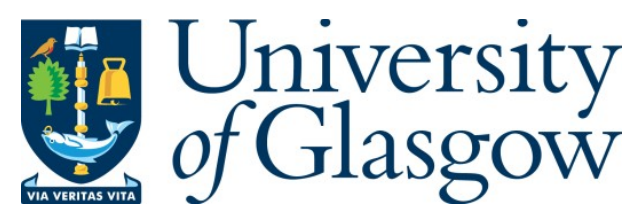

Westaway, R. (2016) The importance of characterizing uncertainty in controversial geoscience applications: induced seismicity associated with hydraulic fracturing for shale gas in northwest England. Proceedings of the Geologists' Association, 127(1), pp. 1-17.

There may be differences between this version and the published version. You are advised to consult the publisher's version if you wish to cite from it.

http://eprints.gla.ac.uk/119683/

Deposited on: 06 October 2016

Enlighten - Research publications by members of the University of Glasgow http://eprints.gla.ac.uk 


\title{
The importance of characterizing uncertainty in controversial geoscience applications: induced seismicity associated with hydraulic fracturing for shale gas in northwest England
}

\author{
Rob Westaway \\ School of Engineering, University of Glasgow, James Watt (South) Building, Glasgow G12 8QQ, U.K. \\ E-mail: robert.westaway@glasgow.ac.uk
}

\begin{abstract}
Fracking of the Preese Hall-1 well in 2011 induced microseismicity that was strong enough to be felt. This occurrence of 'nuisance' microearthquakes, unexpected at the time, was a major factor resulting in adverse public opinion against shale gas in the UK and was thus of significant political importance. Despite this, and notwithstanding the technical importance of this instance of induced seismicity for informing future shale gas projects, it has received little integrated study; contradictory results have indeed been reported in analyses that lack integration. This instance therefore provides a case study to illustrate how a small but significant multi-disciplinary geoscience dataset may be put to best use, including how best to quantify uncertainties in key parameters, which may themselves be relatively poorly quantified but whose values may significantly affect the ability to understand the occurrence of induced seismicity. The best-recorded event in this induced microearthquake sequence (at 08:12 on 2 August 2011) is thus assigned an epicentre circa British National Grid reference SD 377 358, south of the Preese Hall-1 wellhead, a focal depth of $2.5 \mathrm{~km}$, and a focal mechanism with strike $030^{\circ}$, dip $75^{\circ}$, and rake $-20^{\circ}$, this NNE-striking nodal plane being the inferred fault plane. Like other parts of Britain, this locality exhibits high differential stress, with maximum and minimum principal stresses roughly north-south and east-west. This instance indeed fits an emerging trend of the occurrence of relatively large induced earthquakes in localities with high differential stress; such an association was predicted many years ago on the basis of experimental rock mechanics data, so observational confirmation might well have been anticipated and should thus not have been unexpected. Many steep faults, striking NNE-SSW or NE-SW, mostly Carboniferous-age normal faults, are present; the stress field is favourably oriented for their leftlateral reactivation, southward leakage of fracking fluid into one such fault having presumably caused the induced seismicity. Given the pervasive presence of similarly-oriented faults, future occurrences of similar induced seismicity should be planned for; they pose a significant technical challenge to any future UK shale-gas industry.
\end{abstract}




\section{Keywords:}

UK, England, induced seismicity, fracking, Preese Hall, shale gas

\section{Highlights:}

The location and focal mechanism of this induced seismicity are re-determined A probable Carboniferous-age normal fault experienced left-lateral reactivation Faulting with favourable orientation for reactivation is pervasive in $\mathrm{N}$ England Relatively large-magnitude induced activity correlates with high differential stress

\section{Introduction}

The first project to apply hydraulic fracturing for the development of shale gas in the UK, utilizing the Bowland Shale Formation and other Early Carboniferous shales (Table 1), took place in the spring of 2011 from the Preese Hall-1 borehole (wellhead at British National Grid [BNG] reference SD 37525 36584) near Blackpool in northwest England (Fig. 1). The associated 'fracking' caused induced seismicity including microearthquakes with magnitude $\left(M_{L}\right)$ up to 2.3 (e.g., Galloway, 2012), two of which were large enough to have been felt. Such activity, within the usually relatively aseismic continental crust of Britain, resulted in intense public concern and led to the imposition of a UK government moratorium on fracking, which lasted more than a year. Shale gas and fracking remain controversial topics in the UK; for example, in January 2015 the Scottish government imposed a second moratorium, covering development in Scotland of unconventional energy technologies including shale gas (e.g., Freeman, 2015), citing in part the uncertainties involved. Characterization of any site involves investigating a complex 3-D rock volume, which is anisotropic and heterogeneous at multiple scales, primarily on the basis of 1-D wellbores and geophysical data with limited resolution. Conceptual geological models summarizing any such characterization attempt are inherently uncertain (Bond et al., 2007a; 2012; Lindsay et al., 2013). In areas of geoscience where the 'social licence to operate' requires a high level of public confidence in geological models (e.g., onshore oil and gas; onshore carbon capture and storage; and radioactive waste disposal), it is essential to identify the sources of potential uncertainty and to try to minimize these uncertainties, while being transparent about the sources and magnitude of the uncertainties.

\section{Table 1 here:}

\section{Figure 1 here: Map of study locality}


Injection of fluid under high pressure, during fracking, alters the state of stress around a borehole, potentially bringing adjacent pre-existing planes of weakness to the condition for failure. To characterize the nuisance arising from this cause, as a result of fracking at a given site, the operator will have to evaluate many parameters, including the current stress state, the likely magnitude of the stress changes caused by the hydraulic fracturing, the location, size and orientation of any planes of weakness that might act as potential slip planes, how close they are to slipping, whether the imposed changes to the state of stress might bring them to the condition for failure, and what size (expressed as magnitude or seismic moment) of induced earthquake might result from this. The data available to establish the likelihood that a given frack job will cause induced seismicity strong enough to be felt are subject to inherent uncertainties. In onshore applications, geological models are usually based on geological mapping and on borehole and/or seismic reflection data. Geological maps are based in turn on interpretations of surface exposures (which in the UK may well be decades old, so may not include information from new exposures resulting, for example, from roadbuilding), and can therefore include biases (Bond et al., 2007b). Seismic reflection data may be 2-D or 3-D images of geological features with varying acoustic properties. Their vertical resolution limit is $\sim 10 \mathrm{~m}$ (estimated as $1 / 8$ of the wavelength of the seismic waves used, which is $\sim 100 \mathrm{~m}$ for waves of frequency $\sim 40 \mathrm{~Hz}$ in rock with a seismic velocity of $\sim 4000 \mathrm{~m} \mathrm{~s}^{-1}$; cf. Widess, 1973; Chopra et al., 2006); features below this size cannot be imaged. A borehole is essentially a complete record of the rocks along a 1-D transect. However, because it is 1-D it can provide no information about lengths or areas of features, such as fractures and faults, which cut the borehole. Down-hole tools and any core that is returned to the surface can provide in-situ stress data (e.g., from borehole breakouts or drilling-induced tensile fractures), very detailed ( $\mathrm{cm}$ to $\mathrm{mm}$-scale) data on stratigraphy, and rock samples for mechanical testing. Background microseismic activity provides data on current local stress state (from focal mechanisms), and locations of faults (thus 'illuminating' geology; e.g., Pytharouli et al., 2011). The relatively sparse permanent seismograph network spanning the UK (Fig. 1; inset), operated by the British Geological Survey (BGS), had, in 2011, a routine detection threshold for earthquakes of magnitude $\sim 1.5$, but due to variable levels of background noise could only offer 'complete' detection circa magnitude 2.5 (e.g., Galloway, 2012); temporary local networks can detect events of lower magnitudes.

The maximum magnitude of the induced microearthquakes that can be caused by any instance of fracking for shale gas is limited by the volume of fluid injected during each frack job (e.g., McGarr, 2014; Westaway and Younger, 2014). In the UK, the environmental permit for each borehole where fracking for shale gas is to be undertaken, a regulatory requirement administered by the UK 
government Department of Energy and Climate Change, specifies the maximum volume of fluid permitted to be injected in any individual frack job. It thus effectively sets an upper limit to the magnitude of any induced earthquake that might result. The strength of any associated ground vibration depends on this upper bound to magnitude, on the orientation of the fault that provides this seismic source, and on distance from the seismic source (e.g., Westaway and Younger, 2014), which for nearby points on the Earth's surface is determined primarily by the depth of the induced seismicity, which will itself approximate the depth at which the fracking has been undertaken. Regulation of injected fluid volume thus effectively limits the effects of induced seismicity, making it a nuisance rather than a hazard, with ground vibration strong enough to be felt but insufficiently strong for any injuries to people or damage to property to be likely. Nonetheless, as already noted, even felt effects of induced earthquakes are considered a significant issue in the UK. I shall use the Preese Hall induced seismicity as a case study to discuss the uncertainties affecting estimation of the parameters (stress field orientation, location, seismic source orientation, etc.) that influence the nuisance caused by fracking.

Following this occurrence of induced seismicity, a number of consultancy reports were commissioned (e.g., de Pater and Baisch, 2011; Eisner et al., 2011; Harper, 2011; Green et al., 2012; Seismik, 2012), which documented many details regarding the local stratigraphy (Fig. 2) and geological structure (Fig. 3), and academic publications have followed (O'Toole et al., 2013; Clarke et al., 2014). Multiple determinations have thus been made of a number of the essential parameters that describe this induced seismicity. However, many of these outputs are mutually inconsistent and there has been no engagement between the different authors aimed at achieving any resolution. As a result, no consensus currently exists regarding these parameters; it is thus not at all clear from these existing presentations which of the mutually inconsistent solutions are correct, nor where genuine uncertainties lie regarding the interpretation of this rather small and non-optimal dataset.

\section{Figure 2 here: stratigraphic column and stress field diagram}

\section{Figure 3 here: legacy seismic section}

Accurate and transparent communication of uncertainties around geological models are essential to gain public trust in the ability of the geoscience community to 'know what's down there'. I have therefore revisited this dataset, attempting to resolve, where possible, the discrepancies between the different previous interpretations. I thus show that some of the differences relate to use of 
different subsets of the available data, and some to different choices of how to interpret individual items of data, but others are consequences of significant mistakes made during previous analyses.

The present reassessment of the Preese Hall case study has indeed been prompted by the recent publication on it by Clarke et al. (2014). Preliminary versions of some of the data thus presented have already been made public, for example in the de Pater and Baisch (2011), Eisner et al. (2011), Galloway (2012) and Seismik (2012) reports. Clarke et al. (2014) note in their acknowledgements that these documents have featured in submissions to government (such as those by Mair et al., 2012, and Masters et al., 2014), but do not make clear that in their publication they have changed aspects of the interpretation, so that some of the information previously placed in the public domain is not supported by their most recent analysis. This creates the potential for considerable confusion. Clarke et al. (2014) also give the impression that all the data underpinning their analysis has been placed in the public domain, when some of it has not been; the data sources from which some of their conclusions are drawn are inaccessible. Regulations now require geological data pertaining to shale gas exploration in the UK to be placed in the public domain after a six-month embargo (UK Parliament, 2014), but do not apply retrospectively to the activities in 2011. It has also become apparent that Clarke et al. (2014) have made a number of mistakes during their analysis, and that these are too complex to be covered by the publication of an erratum.

The argument that uncertainties in geological knowledge make shale gas a relatively risky technology for the UK is often used by environmental activists. In this regard, the Clarke et al. (2014) paper raises several significant issues regarding the integrated portrayal of relevant geological data, pertaining to microseismicity, structural geology (from seismic reflection surveys), and geomechanics (pertaining to the state of stress in the Earth and how it is modified by the fracking process to enable slip on the seismogenic fault). Having outlined these issues, I will then discuss new hypocentre and focal mechanism determinations, which avoid some of the difficulties evident with existing solutions. Finally, I will consider some of the implications of this work for issues that arise when fracking for shale gas in a region, such as northern England, which is under relatively high differential stress. Although focused on UK-related topics, this study has wider implications, given the recent occurrence of the first microearthquake in the USA associated with fracking for shale gas and large enough to be felt (the $M_{L} 3.0$ Poland Township, Ohio, event of 10 March 2014; Skoumal et al., 2015); this likewise occurred in a region of high differential stress (e.g., Bauer et al., 2005). 


\section{The Preese Hall induced seismicity}

Before proceeding farther it is important to be clear as to terminology. The mechanisms whereby human activities can affect seismicity have been widely discussed in recent years (e.g., Seeber, 2002; Westaway, 2002, 2006, in press; Klose 2007a,b, 2013; Ellsworth 2013; Rubinstein and Mahani, 2015; see below). Following Klose (2013), an 'anthropogenic earthquake' can be defined as any seismic event for which a human activity can reasonably be shown to be the cause, or at least a major influence on timing. Anthropogenic earthquakes can in turn be subdivided into 'triggered' and 'induced' events; a triggered event is one that would have occurred anyway, because the state of stress in the area was tending towards the condition for shear failure, or slip on an active fault, so that the human activity merely brought the earthquake forward in time or 'advanced the clock'. An earthquake is 'induced' if there is no reason to consider that, in the absence of human activity, the state of stress in the area was heading towards the condition for shear failure: in other words, without the human activity the earthquake would never have occurred. Since the cause-and-effect connection between fracking and the Preese Hall seismicity is clear (e.g., Clarke et al., 2014; Westaway, in press), and no-one has demonstrated any mechanism whereby this instance of fracking merely 'advanced the clock' for seismicity that would otherwise have occurred anyway, it is evident that this instance is consistent with this definition of induced seismicity.

However, other definitions of induced seismicity also exist, for example those by McGarr et al. (2002) and Rubinstein and Mahani (2015). As Westaway (in press) has discussed, these alternative suggestions can have problematic consequences; adherence to the standard definition is therefore recommended. Furthermore, one of the reviewers of this manuscript, Professor Terry Engelder, has made clear that he follows yet another definition, whereby induced (or 'wet') microseismic events are defined as those associated with opening of and slip on fractures, caused by the stimulation fluid flowing into the fault plane and reducing its effective normal stress (cf. Simpson and Negmatullaev, 1981). On the other hand, triggered (or 'dry') microseismic events are defined as those that are driven by the change in the state of stress, associated with the strain surrounding the zone of induced fractures, resulting in a larger shear stress across the fault plane (cf. Pomeroy et al., 1976). In terms of the standard definition of induced seismicity that I have adopted, both these 'wet' and 'dry' mechanisms count as 'induced'. Nonetheless, this distinction between 'wet' and 'dry' mechanisms, and the different directions of approach of the state of stress to the failure envelope that they represent, is useful; they might indeed be adopted as distinct categories of induced seismicity, which can be resolved following detailed consideration of physical mechanisms. 
To facilitate later discussion, a brief summary of the activities at Preese Hall in 2011 is provided here, drawing upon the more detailed account by de Pater and Baisch (2011). The first frack job was on 28 March 2011; it involved injection of $1969 \mathrm{~m}^{3}$ (12,385 barrels) of fluid into borehole perforations centred about a depth of $2723 \mathrm{~m}(8935 \mathrm{ft})$. No induced seismicity was detected, but at this stage no seismographs were deployed locally, so detection was entirely dependent on the BGS permanent seismograph network. The second frack job on 31 March 2011 involved injection of $2339 \mathrm{~m}^{3}(14,710$ barrels) of fluid into borehole perforations centred circa $2662 \mathrm{~m}(8735 \mathrm{ft})$. It resulted in multiple induced earthquakes including the largest of the sequence, of $M_{L} 2.3$, which occurred at 02:34 on 1 April ( 10 hours after the end of fluid injection) and was felt by many people, its maximum effect being at intensity 4 on the EMS scale (Galloway, 2012). Detection still depended on the BGS network, but since their nearest seismograph station was $\sim 80 \mathrm{~km}$ away, accurate location was impossible; BGS thus located this event at a depth of $3.6 \mathrm{~km}$ beneath BNG reference SD 3577 3732, 2 km WNW of Preese Hall (Galloway, 2012; Fig. 1). Although Galloway (2012) has stated that this seismicity was 'immediately suspected to be linked to hydraulic fracture injections at the Preese Hall well', this was initially by no means clear, not least due to this and other inaccurate hypocentral determinations. Nonetheless, Keele University installed two seismographs near Preese Hall in early April, which were joined by two more (stations AVH and HHF) installed by BGS a few days later. However, initially no local earthquakes were recorded by any of these instruments. For the third frack job on 12 April, $800 \mathrm{~m}^{3}$ (5031 barrels) of fluid was injected into borehole perforations centred about a depth of $2577 \mathrm{~m}$ (8455 ft), but resulted in no immediate induced seismicity; as a result, the Keele University stations were removed later in the month although the BGS equipment continued operating and indeed recorded three local events in the $\mathrm{M}_{\mathrm{L}}-1$ to -2 range during early May.

The fourth frack job took place on 26 May, with $1684 \mathrm{~m}^{3}$ (10,590 barrels) of fluid injected into borehole perforations centred about a depth of $2477 \mathrm{~m}(8125 \mathrm{ft})$, resulting in the resumption of seismicity, including the second largest event of the sequence, at 00:48 on 27 May (again 10 hours after the end of fluid injection). BGS reported that two people in the vicinity felt this event and determined its hypocentre at $2.3 \mathrm{~km}$ depth beneath BNG reference SD 37463619 (Galloway, 2012), although with no stated margins of uncertainty. This relatively accurate location (Fig. 1), facilitated by local stations AVH and HHF being operational, nonetheless made clear the causal connection between the fracking and the seismicity. The fifth frack job, later on 27 May, involved injection of $1569 \mathrm{~m}^{3}$ (9870 barrels) of fluid into borehole perforations centred about $2409 \mathrm{~m}$ (7905 ft) depth, which resulted more induced earthquakes; at this point fracking operations were discontinued. Nonetheless, BGS installed two more temporary stations (EVW and PRH) nearby, which - along with 
AVH and HHF - recorded a final small $\left(\mathrm{M}_{\mathrm{L}}-0.2\right)$ induced microearthquake at 08:12 on 2 August 2011; Galloway (2012) provided hypocentral co-ordinates for this event, which were the same as for the 27 May event and again have no stated margins of uncertainty, but did not disclose the arrival time data on which this location was based.

The similarity in seismic waveforms for the events recorded by the local stations means that they indeed occurred in close proximity and had very similar focal mechanisms (e.g., de Pater and Baisch, 2011; Clarke et al., 2014); this similarity can be confirmed by inspection of the seismograms in these publications. Analysis of the 2 August 2011 event thus helps to constrain the larger microearthquakes that were less well recorded. The hypocentral co-ordinates reported by Galloway (2012) are $\sim 400 \mathrm{~m}$ south of the Preese Hall-1 wellhead (Fig. 1) and at roughly the depth at which the later frack jobs took place. Given the volume of fracking fluid injected during each frack job (1969, $2339,800,1684$, and $1569 \mathrm{~m}^{3}$, respectively, for frack stages 1-5 depicted in Fig. 2(a), according to de Pater and Baisch, 2011) it can be anticipated that - if equidimensional - each induced fracture network created had vertical and horizontal dimensions of maybe $\sim 300 \mathrm{~m}$ (e.g., Fisher and Warpinski, 2012; Westaway and Younger, 2014). Given the state of stress in the area, with the vertical stress intermediate between the two principal horizontal stresses (see below; section 3.1), the induced fractures will have developed in vertical planes perpendicular to the minimum principal stress, which is locally roughly east-west (see below; section 3.1); in a homogenous rock mass, if the bottom hole pressure (BHP) of the fracking fluid was the minimum necessary for a given frack job to initiate fracturing, then the resulting fractures will have propagated upward and outward, whereas if the BHP exceeded this threshold they will have propagated in part upward and in part downward, as well as outward. Davies et al. (2013) have identified several candidate mechanisms for induced seismicity from fracking for shale gas. Given the local context, with vertical induced fractures oriented N-S expected in a locality with steep normal faults, inherited from crustal extension during the Early Carboniferous, which typically strike NNE-SSW or NE-SW (Fig. 3), a plausible candidate mechanism is for the induced fracture networks created by the second, fourth and fifth frack jobs to have intersected one of these ancient normal faults and to have each reactivated patches of it (see also below). The hypocentral co-ordinates from Galloway (2012) thus suggest that it was the southward component of fracture propagation that led to these fault intersections developing, a deduction that is supported by the present re-analysis of this dataset (Fig. 1; see below, section 4).

Nonetheless, the potential importance of the aforementioned 'dry' mechanism for induced seismicity (i.e., as a result of changes to the state of stress resulting from the opening of fractures) 
also warrants attention, given that the Davies et al. (2013) analysis of scenarios whereby fluid injection might induce seismicity (which has had a significant influence on this topic, at least in the UK) only considered the 'wet' mechanism. Strain associated with induced fractures was first measured decades ago and can be modelled using a range of techniques (e.g., Evans et al., 1982; Davis, 1983; Vasco et al., 2002; Vasco and Ferretti, 2005) to help constrain underlying physical mechanisms. However, the lack of geodetic monitoring of the Preese Hall project means that this method of analysis cannot be used in this instance. For most of the duration of this project no microseismic monitoring was in place, either, but the aforementioned seismographs were belatedly installed, and produced the principal dataset that can bear upon analysis to link the observed microseismicity with the associated rock mechanics. It has become familiar in U.S. practice for such analyses to regard induced microseismicity caused by fracking as a consequence of propagation of fluid pressure pulses (which may not be accompanied by bulk movement of fluid) through the rock mass (e.g., Geiser et al., 2012; Lacazette et al., 2013; Geiser and Leary, 2014). McClure (2015) has indeed argued that this general mechanism can account for time delays between injection and the associated seismicity; in his view such a delay can be attributed to the time it takes for a fluid pressure pulse to travel along a fracture network, reflect off its end, and travel back again, to add to the existing pressure near the injection point. However, as used in industry, this technique combines proprietary elements with assumptions about rock mechanics that are not all generally accepted (cf. Lacazette et al., 2013). In addition, the velocity of the fluid pressure pulses was reported by Geiser and Leary (2014) as 'tens of $\mathrm{m} \mathrm{s}^{-1}$ ', but seems to be lower, $\sim 3 \mathrm{~m} \mathrm{~s}^{-1}$, for the McClure (2015) analysis. Even so, the latter study can only account for post-injection time delays of a few minutes, rather than the ten-hour delays evident at Preese Hall. Thus, although this physical mechanism may be applicable in some situations, it is not considered further here.

\section{Portrayal of geological data}

As already noted, several candidate physical mechanisms have been proposed whereby fracking for shale gas can cause induced seismicity (e.g., Davies et al., 2013). In order to understand the processes responsible for the Preese Hall occurrence, diverse geological information is required. This includes the local state of stress before fracking was begun, to what extent this state of stress was modified by the high-pressure injection of fracking fluid into the rocks, the structural geology, and the location and source orientation of the induced seismicity. It is apparent that only limited data are available for Preese Hall regarding some of these aspects, for example, because no seismographs were deployed locally during most of this induced microearthquake sequence. Conversely, for other forms of data, such as in situ stress measurements, different authors have reported contradictory 
results. Despite difficulties regarding the quality and quantity of the available data, the importance of the topic makes it worthwhile both to make best use of the available data and to identify any uncertainties that remain.

\subsection{State of stress}

It is well established that the maximum principal stress $\left(\sigma_{1}\right)$ is roughly north-south in northern England (e.g., Evans and Brereton, 1990; Cartwright, 1997; Baptie, 2010). It has long been known that the differential stress in Britain is relatively high; for example, its magnitude and orientation have influenced the design of coal mines (Cartwright, 1997). In situ measurements of the magnitude and orientation of the local stress were made in the Preese Hall-1 borehole before fracking took place, using borehole breakouts and drilling-induced tensile fractures (Baker Hughes, 2011; Harper, 2011). Baker Hughes (2011) reported estimates for $\sigma_{1}$ of $173 \pm 7^{\circ}$ from the World Stress Map (WSM) and $173 \pm 10^{\circ}$ from their analysis of the orientation of these drilling-induced tensile fractures in the depth range 1417-2094 m (Fig. 2(a)). These estimates have been reported as definitive in recent documentation to inform planning applications for future shale gas activities in the area (Cuadrilla, 2014a, p. 46 and 50; Cuadrilla, 2014b, p. 45 and p. 51). Clarke et al. (2014) indeed reported $\sigma_{1}$ locally as $173^{\circ}$, with no error margin, citing de Pater and Baisch (2011) as the source. However, this citation is in fact referring to Baker Hughes (2011), which is listed on Cuadrilla's website as 'Appendix 1' of de Pater and Baisch (2011), and documents indicators of the state of stress at much shallower depths than those at which the fracking was subsequently carried out (Fig. 2(a)). On the other hand, Harper (2011) reported that the best estimate of $\sigma_{1}$ is provided by drilling-induced tensile fractures documented deeper, in the depth range 2246-2751 m (i.e. around the depth where fracking was later undertaken; Fig. 2(a)), but stated this to be $\sim 188^{\circ}$, not $173^{\circ}$. Harper (2011) indeed reported that both the borehole breakouts and drilling-induced tensile fractures in this depth range indicate $\sigma_{1}$ $188 \pm 16^{\circ}$, whereas using only the latter data the mean value is slightly different, $187^{\circ}$ (with no stated margin of uncertainty). It is important to reconcile these different estimates for $\sigma_{1}$, because any future analysis of the geomechanics of this fracking process will require accurate knowledge of this quantity.

Notwithstanding the report by Baker Hughes (2011) of a N7 $7^{\circ}-S 7^{\circ} \mathrm{E} \sigma_{1}$ at Preese Hall from WSM data, recent WSM outputs (e.g., Heidbach et al., 2010) in fact report $\sigma_{1}$ as circa $\mathrm{N} 35^{\circ} \mathrm{W}-\mathrm{S} 35^{\circ} \mathrm{E}$ in northwest England. The online gridded WSM dataset (GFZ, 2015) indeed lists best estimates of $\mathrm{N} 34.7^{\circ} \mathrm{W}-\mathrm{S} 34.7^{\circ} \mathrm{E}$ at $53.75^{\circ} \mathrm{N} 2.75^{\circ} \mathrm{W}$ (i.e., circa SD 506 284, $15 \mathrm{~km}$ ESE of Preese Hall) and N33.9 $\mathrm{W}$ $\mathrm{S} 33.9^{\circ} \mathrm{E}$ at $53.75^{\circ} \mathrm{N} 3.25^{\circ} \mathrm{W}$ (i.e., circa SD $177289, \sim 21 \mathrm{~km}$ WSW of Preese Hall). However, it is 
evident from the raw data (also available from GFZ, 2015) that these outputs are based on interpolation between sparse data of diverse orientations. Thus, for example, at Burton-in-Kendal in SE Cumbria ( $54.20^{\circ} \mathrm{N} \sim 2.71^{\circ} \mathrm{W}$; circa SD 538785 ; $\sim 46 \mathrm{~km}$ from Preese Hall to N21 ${ }^{\circ}$ ), GFZ (2015) notes a $\sigma_{1}$ measurement of $\mathrm{N} 13^{\circ} \mathrm{E}-\mathrm{S} 13^{\circ} \mathrm{W}$. Conversely, at Sellafield in west Cumbria $\left(\sim 54.42^{\circ} \mathrm{N}\right.$ $\sim 3.46^{\circ} \mathrm{W}$; circa NY054037; $75 \mathrm{~km}$ from Preese Hall to $\sim \mathrm{N} 35^{\circ} \mathrm{W}$ ), GFZ (2015) lists nine measurements of $\sigma_{1}$ (at azimuths of $146^{\circ}, 149^{\circ}, 151^{\circ}, 155^{\circ}, 155^{\circ}, 158^{\circ}, 158^{\circ}, 161^{\circ}$, and $175^{\circ}$ ), which yield a mean value of $156^{\circ}\left( \pm 8^{\circ}\right.$ as $\pm 1 \sigma ; \pm 6^{\circ}$ as $\left.\pm 2 \mathrm{~s}\right)$ or $N 24 \pm 6^{\circ} \mathrm{W}-\mathrm{S} 24 \pm 6^{\circ} \mathrm{E}( \pm 2 \mathrm{~s})$. It is thus apparent that $\sigma_{1}$ varies significantly across this region, making it preferable to rely on local measurements from the Preese Hall-1 borehole rather than inferences using data from more distant localities.

\section{Table 2: reanalysis 1 of stress data}

\section{Table 3: reanalysis 2 of stress data}

Regarding the local measurements, there are the aforementioned analyses that yielded estimates for $\sigma_{1}$ from drilling-induced tensile fractures of $173 \pm 10^{\circ}$ (Baker Hughes, 2011) and $\sim 187$ or $188^{\circ}$ (Harper, 2011), as well as the combined dataset of borehole breakouts and drilling-induced tensile fractures that yielded $188 \pm 16^{\circ}$ (Harper, 2011). To try to understand the differences between these estimates I have looked again at the raw data (Tables 2 and 3). My reanalyses indicate a mean $\sigma_{1}$ of $176 \pm 5^{\circ}( \pm 2 \mathrm{~s})$ or $\mathrm{N} 4 \pm 5^{\circ} \mathrm{W}-\mathrm{S} 4 \pm 5^{\circ} \mathrm{E}( \pm 2 \mathrm{~s})$ for the Baker Hughes (2011) dataset (Table 2) and of $187 \pm 3^{\circ}$ $( \pm 2 \mathrm{~s})$ or $\mathrm{N} 7 \pm 3^{\circ} \mathrm{E}-\mathrm{S} 7 \pm 3^{\circ} \mathrm{W}( \pm 2 \mathrm{~s})$ for the Harper (2011) dataset (Table 3). These two estimates therefore differ significantly (at a 95\% confidence level). Others (e.g., Roche et al., 2015) have noted that the state of stress elsewhere shows significant vertical variations within stratigraphic sequences in which one formation undergoes fracking. In my view it is thus preferable to adopt, for the purpose of geomechanical analyses of the Preese Hall fracking, the result based on the Harper (2011) dataset, since these data originated from the depth range where the fracking was undertaken (Fig. 2). Since hydraulic fractures develop in the plane perpendicular to the minimum principal stress, it is therefore to be expected as a best estimate that these propagated away from the Preese Hall-1 borehole in the direction $\mathrm{N} 7 \pm 3^{\circ} \mathrm{E}-\mathrm{S} 7 \pm 3^{\circ} \mathrm{W}( \pm 2 \mathrm{~s})$.

As regards stress magnitudes, de Pater and Baisch (2011) first noted that, measured in the Preese Hall-1 well, $\left|\sigma_{1}\right|$ is $\sim 60 \%$ larger than the minimum horizontal stress $\left(\sigma_{3}\right)$, with the vertical stress $\left(\sigma_{2}\right)$ taking intermediate values. Cuadrilla $(2014 a, b)$ confirmed this, reporting that at $2500 \mathrm{~m}$ depth, $\left|\sigma_{1}\right| \approx 70 \mathrm{MPa},\left|\sigma_{2}\right| \approx 60 \mathrm{MPa}$, and $\left|\sigma_{3}\right| \approx 45 \mathrm{MPa}$ (Fig. 2(b)). However, O'Toole et al. (2013) argued on the contrary that the very low seismic velocity anisotropy $(\sim 1 \%)$ in this vicinity indicates very low 
differential stress magnitudes. Given that the in situ stress measurements are what they are, their argument is evidently wrong, and so should not be used in future; nonetheless, from directions of fast shear-wave polarization $\mathrm{O}^{\prime} T o o l e$ et al. (2013) measured $\sigma_{1}$ as $193 \pm 8^{\circ}( \pm 2 \mathrm{~s})$ or $\mathrm{N} 13 \pm 8^{\circ} \mathrm{E}-\mathrm{S} 13 \pm 8^{\circ} \mathrm{W}$ $( \pm 2 s)$, consistent with the data from Harper (2011) (Table 3).

\subsection{Stress perturbation due to pressure of fracking fluid}

Hydraulic fracturing requires the pressure of fracking fluid to exceed the minimum principal stress at the depth of fracking (e.g., Fisher and Warpinski, 2012; Westaway and Younger, 2014). At a depth of $\sim 2500 \mathrm{~m}$, it thus requires a BHP of at least $\sim 45 \mathrm{MPa}$, tens of megapascals higher than the expected hydrostatic pressure at this depth. de Pater and Baisch (2011) have presented a series of graphs illustrating variations in measured well head pressure (WHP) and corresponding variations in BHP, indicating values of up to $~ 9000$ psi or $\sim 62 \mathrm{MPa}$, which they have derived from WHP by calculation, although they did not explain these calculations. I have attempted to replicate their analysis using the standard method for this type of calculation, but have been unable to replicate their results (I obtain values that differ from theirs for each of the fracking stages undertaken by up to 10 MPa).

Pending resolution of this issue, it is evident from the foregoing that the actual BHP values used in these instances of fracking must be considered subject to considerable uncertainty. Moreover, the precise values used determine the geometry of the network of hydraulic fractures that was induced; as already noted, if BHP was the minimum value required to initiate fracture propagation, then the fractures will have propagated upward as well as outward, whereas if it significantly exceeded this threshold then fracture propagation would also have occurred downward (e.g., Fisher and Warpinski, 2012; Westaway and Younger, 2014). In a homogenous rock mass, the vertical extent of the fracture network is determined by the volume of fracking fluid used in each fracking stage; for the volumes used in this instance (listed in section 2) it will amount to several hundred metres (say, $\sim 300 \mathrm{~m}$ ) (e.g., Westaway and Younger, 2014). Uncertainty in BHP thus results in uncertainty in the location of the induced fracture network, thus impacting on uncertainty in any resulting geomechanical interpretation. The layered stratigraphy (Fig. 2(a) presents a further complicating factor, it having long been recognized both observationally and via numerical modelling (e.g., Evans et al., 1989; Warpinski, 1989; Brenner and Gudmundsson, 2004) that the different rheological properties of shales and other interbedded rocks such as sandstones and limestones can distribute stress differently, such that lithological boundaries can arrest fractures and thus act as 'frack barriers'. It is indeed evident from Fig. 2(a)) that the vertical extent of the Hodder Mudstone is less than the aforementioned $\sim 300 \mathrm{~m}$ fracture height that would be predicted for a homogenous rock 
mass. Since the underlying and overlying limestone formations are significantly stronger than this mudstone (de Pater and Baisch, 2011), induced fracture development might have been arrested at these inter-formational boundaries, in which case the induced fracture networks would have extended farther sideways (as schematically illustrated in Fig. 1) to accommodate the volume of fracking fluid. Alternatively, if these induced fractures instead propagated vertically into these permeable limestones, additional paths for fluid migration would have been created, potentially complicating analysis of the causal mechanism for the induced seismicity.

I note in passing that Clarke et al. (2014) present a graph (their Fig. 3) labelled as BHP, for the fracking stage that caused the $M_{L}=2.3$ Preese Hall earthquake, with no reference source provided. This graph is in fact taken from de Pater and Baisch (2011; their Fig. 22) but is presented there as a graph of WHP. Nonetheless, Clarke et al. (2014) did not use the pressure values thus illustrated in any quantitative calculations, so no additional errors have resulted from this mistake. This point is mentioned here, because the maximum pressure that Clarke et al. (2014) reported is $\sim 7500$ psi which corresponds to $52 \mathrm{MPa}$; if this point were not mentioned, readers might be puzzled as to the mismatch between the earlier statements that the BHP is subject to considerable uncertainty and the portrayal of precise values for this parameter by Clarke et al. (2014).

\subsection{Seismic reflection evidence for the geometry of the seismogenic fault}

Leakage of fracking fluid into faults, causing a change in the state of stress on the fault in favour of slip, because this fluid is under higher pressure than any pre-existing groundwater within the fault, is a candidate mechanism for induced seismicity (e.g., Davies et al., 2013). As this mechanism had already been recognized long before the Preese Hall-1 project went ahead (e.g., Wohlhart et al., 2006), the Carboniferous sediments in the region were already well known to be pervasively fractured and faulted (e.g., British Coal Corporation, 1997; Pharaoh et al., 2011), and the differential stress in the region was already known to be high from measurements in coal mines (Cartwright, 1997), the possibility of its occurrence might have been investigated before any fracking took place, not least because faults had been identified in the vicinity on seismic sections (e.g., that in Fig. 3). The necessity for such analysis might indeed have become more strongly evident once the in situ stress measurements (mentioned in section 3.1) had revealed that the locality is indeed subject to high differential stress, confirming the assumption that might reasonably have been made from coal industry records. 
Following the occurrence of the induced seismicity, de Pater and Baisch (2011) published part of a west-east seismic section, utilizing data collected in the 1980s, passing $\sim 400 \mathrm{~m}$ north of the Preese Hall-1 well (Fig. 3). Several normal faults are thus depicted in the vicinity of the projection of this well into the section-line. One of these (labelled 1) has a component of downthrow to the west and plots $\sim 1050$ m east of the projected well (point 1 in Fig. 1). This fault has been inferred from other seismic lines (not depicted) to strike at $\sim 220^{\circ}$ (i.e., to dip northwest) and to pass (at the depth of the uppermost Carboniferous sediments; Table 1) $700 \mathrm{~m}$ of east of the wellhead (see, e.g., Fig. 6 of de Pater and Baisch, 2011). A second, smaller, fault (labelled 2) is depicted as offsetting (at a two-way time of $\sim 1.35 \mathrm{~s}$, depicted roughly coincident with the bottom of the Preese Hall-1 well) the top of the Clitheroe Limestone Formation (CLL; Table 1) at a point $\sim 300 \mathrm{~m}$ east of the projected wellhead (point 2 in Fig. 1), with a component of downthrow to the east. If this fault has NE or NNE strike it must project somewhere very close to the well. The same seismic section was, however, interpreted differently by Harper (2011; his Fig. 2.2); in his view a steep east-dipping reverse fault transects the projected position of the Preese Hall-1 borehole into the section-line.

\section{Figure 4 here: Excerpt from Clarke et al. 3-D seismic dataset}

In contrast with these earlier interpretations, Fig. 1 of Clarke et al. (2014) shows a fault of unspecified polarity but with $\sim 030^{\circ}$ strike, dip to the $\mathrm{SE}$, and along-strike length $\sim 5 \mathrm{~km}$, which projects upward to the NW from a depth of $2930 \mathrm{~m}$ at a position $\sim 700 \mathrm{~m}$ east of the wellhead. In Fig. 1 this has been tentatively (?) depicted as a normal fault with downthrow to the SE, consistent with the sense that the Clarke et al. (2014) explanation seems to be striving to convey. However, their Fig. 4 (redrawn, in part, as Fig. 4), which shows an excerpt from a 3-D seismic survey shot in 2012, is different yet again. The horizontal seismic section in this Fig. 4 shows a fault with an apparent $\sim 060^{\circ}$ strike that, likewise, passes $\sim 700 \mathrm{~m}$ east of the Preese Hall-1 wellhead. The annotation states that this horizontal section is not foreshortened, but if the true strike of this fault is $\sim 030^{\circ}$ to match their Fig. 1 then it must be foreshortened north-south by a factor of $\sim 3$, something that Clarke et al. (2014) might usefully have mentioned. Furthermore, although this fault is in roughly the same place as Fault 1 in Fig. 3, Clarke et al. (2014) state that it is a reverse fault dipping southeast, not a normal fault dipping northwest. It is difficult to understand precisely what is the basis of this reinterpretation as their Fig. 4 is unclear, much of its data content being obliterated by interpretations and labelling (cf. Fig. 4). Nonetheless, some seismic reflectors can be seen to be offset or warped with a component of downthrow to the east, suggesting that a normal fault with southeastward dip is in fact present (labelled 'fault (this study)' in Fig. 1; see, also, the discussion in 
the Figure caption). With a $\sim 030^{\circ}$ strike, this fault would project into the section line in Fig. $3 \sim 200 \mathrm{~m}$ east of Fault 2, where no fault with this polarity is evident. Assuming that the cross-section in Fig. 4 has been correctly located (see the Figure caption), it would therefore appear that the fault identified in the 3-D seismic survey reported by Clarke et al. (2014) must die out before the section line in Fig. 3 is reached, rather than extending SW-NE to a total length of $\sim 5 \mathrm{~km}$ as they inferred in their Fig. 1. Likewise, faults depicted in Fig. 3 might well die out within the $\sim 400 \mathrm{~m}$ separation between this seismic section and the Preese Hall-1 well, such that the fault(s) responsible for the induced seismicity (such as that labelled 'fault (this study)' in Fig. 1) are not depicted in Fig. 3. Clearly, another alternative possibility is that Fig. 4 has not been located in the right place on Fig. 1; for example, if in reality its section line coincides with that of Fig. 3, then the co-ordinates of the candidate seismogenic fault recognized on Fig. 4 in the present study would coincide with those of Fault 2 on Fig. 3.

These different possibilities raise the question which, if any, of these fault interpretations, by de Pater and Baisch (2011) (Fig. 3), Harper (2011), or Clarke et al. (2014), is correct. Other factors being equal, one would expect a modern 3-D seismic section, like that in Fig. 4 of Clarke et al. (2014), to be more reliable than 2-D seismic sections from the 1980s. However, given the evident lack of clarity of this particular 3-D seismic section (albeit a clearer version is now available as the present Fig. 4, although with some doubt over its precise location), one might reasonably revert to the older data source. The non-uniqueness of many interpretations of seismic sections, especially those that consider data near the limit of resolution, is widely recognized (e.g., Bond et al., 2007a,b, 2012).

\subsection{Hypocentral co-ordinates and focal mechanisms}

As already noted (Fig. 1), Galloway (2012) placed the hypocentres for both the 27 May and 2 August events some $400 \mathrm{~m}$ south of the Preese Hall-1 wellhead, with a focal depth of $2.3 \mathrm{~km}$. O'Toole et al. (2013) deduced a similar location from their own analysis; Eisner et al. (2011) likewise deduced similar co-ordinates for the 27 May event. On the other hand, Seismik (2012) reported preferred hypocentral co-ordinates for the 2 August event $\sim 500 \mathrm{~m}$ east of the Preese Hall-1 wellhead, at a depth of $\sim 2930 \mathrm{~m}$, with uncertainties of $\sim 120 \mathrm{~m}$ in horizontal position and $\sim 240 \mathrm{~m}$ in depth and Clarke et al. (2014) stated similar co-ordinates. Neither of these studies mentioned that the hypocentres that they determined differ from what others had previously determined. Induced seismicity east of this well would be puzzling, because there would be no clear causal mechanism, in contrast with induced seismicity south of the well that - as already noted - can be readily explained in terms of induced fracture development within the prevailing stress field. Although it was not 
mentioned in either of these studies, the rationale for epicentral co-ordinates to the east of the well was to account for the arrival time of seismic P-waves at station EVH that is to the east of the wellhead, subject to the assumption of no lateral variations in seismic velocity (see below, section 4, also the online supplement). As regards vertical variations in seismic velocity, it is apparent that Clarke et al. (2014) assumed seismic velocities representative of crustal basement around the depths of fracking, when it should be apparent that velocities representative of Bowland Shale should have been adopted. Their unexpectedly deep hypocentre is evidently a consequence of this assumption of a seismic velocity model that is too fast (see below, section 4 , also the online supplement). The best fitting focal depth thus adjusts shallower when a more appropriate velocity model is used, avoiding any necessity to devise any conceptual model for the occurrence of induced seismicity at a depth hundreds of metres deeper than the fracking.

Preliminary focal mechanisms for the 2 August 2011 event and other induced microearthquakes at Preese Hall were presented in the Eisner et al. (2011) and Seismik (2012) reports. Some variability was evident in these solutions due to different possible choices of picks of polarities of seismic phases and different choices of hypocentral locations, which determine where the nearby temporary seismograph stations plot on the focal sphere about each hypocentre. The differences between these preliminary solutions and that by Clarke et al. (2014) are discussed in detail in the online supplement.

Clarke et al. (2014) concluded that the 2 August 2011 event has a focal mechanism with strike $040^{\circ}$, $\operatorname{dip} 70^{\circ}$ and rake $-150^{\circ}$. However, the depiction of this focal mechanism in their Fig. 4, reportedly using a standard lower focal hemisphere projection, does not match this set of angles (see Fig. S1 in the online supplement for more detail). Clarke et al. (2014) concluded that this nodal plane with $040^{\circ}$ strike and $70^{\circ}$ dip towards $130^{\circ}$ was the fault plane, but inferred that the source involved a component of left-lateral slip, when it should be evident that a rake of $-150^{\circ}$ indicates a component of right-lateral slip. In any case, as drawn, their diagram does not have a nodal plane that dips to the southeast; it has one that dips to the northwest, on which the component of strike-slip would be left-lateral if it were the fault plane. Similar mixups apply to the focal mechanisms for this and other events reported in the Eisner et al. (2011) and Seismik (2012) reports, and indeed in publications by the same team on microseismicity elsewhere, such as that by Eisner et al. (2010). I have investigated the possibility that they have drawn upper focal hemisphere projections although these are labelled as 'lower focal hemisphere' but, if so, they must also have defined rake using a left-handed sign convention, rather than the right-handed standard used in earthquake seismology; if this is indeed 
so then their focal mechanism in fact has strike $040^{\circ}$, dip $70^{\circ}$ and rake $-30^{\circ}$. However, if this is the case then other problems also exist with their solution, since the polarities of P- and S-phases that are predicted, for this interpretation, at some of the temporary seismograph stations, do not correspond to the polarities that Clarke et al. (2014) have stated are expected for their solution (see the online supplement). Since it has proved intractable to resolve precisely what has in fact 'gone wrong' with their solution, I have revisited the dataset to determine my own solution (see below; section 4).

\section{Revised hypocentre and focal mechanism determinations}

As has been noted above, there is currently no satisfactory solution for the hypocentre or focal mechanism for the 2 August 2011 event, and thus for the induced seismicity in general. I have therefore revisited the dataset, determining these over again. To avoid introducing further complexity into an already quite confused situation, I have made use of the filtered seismograms that Clarke et al. (2014) have provided, rather than re-examining the raw digital seismograms. The procedure that I have followed is explained in full in the online supplement, a summary of this reinterpretation procedure being provided here.

Using the crustal velocity model in Table 1 I have obtained a revised location for the 2 August 2011 event, with epicentre circa BNG reference SD 37723584 and focal depth $2500 \mathrm{~m}$. The solution fits the observed arrival times at $\mathrm{AVH}, \mathrm{HHF}$ and $\mathrm{PRH}$ very closely but the predicted hypocentre predicts the P-wave arrival time at EVW $>0.2 \mathrm{~s}$ too late. A possible solution to this mismatch would be to adjust the hypocentre northeastward, closer to EVW; indeed, epicentral co-ordinates near those suggested by Seismik (2012) and Clarke et al. (2014) would, formally, give a better overall fit to the data. However, the westward component of dip evident at localities to the northeast of the Preese Hall-1 borehole in Fig. 3 would result in the relatively high-velocity Upper Carboniferous sediments reaching to shallower depths than are predicted for the velocity model in Table 1 . Numerical tests indicate that this effect on its own can result in P-wave travel times to EVW that are $\sim 0.1 \mathrm{~s}$ faster. By changing the angles of refraction and thus the length of ray-paths, the introduction of westward dipping boundaries between layers of the part of the seismic velocity model between Preese Hall and EVW, to reflect the underlying structure (Fig. 3), would, on its own, likewise result in P-wave travel times to EVW that would be $\sim 0.1 \mathrm{~s}$ faster. General adjustments to the depths of the layer boundaries adopted in the velocity model (Table 1) to better reflect the local geology (see Table 1 caption) can also, on its own, readily result in travel times to each of the stations that differ from those currently calculated by $\sim 0.1 \mathrm{~s}$ or more. Furthermore, the westward components of dip 
depicted in Figs. 3 and 4 result from WNW dip (e.g., de Pater and Baisch, 2011) and, thus, WNW thickening of the younger (post-Variscan; Fig. 2(b)) sediments with relatively slow seismic velocities. I suggest that each of these factors, in some combination, can account for the mismatch in the current solution between EVW and the other stations, via a combination of small adjustments to the hypocentral co-ordinates, slightly faster travel times to EVW and HHF, and slightly slower travel times to other stations. The variations in Poisson's ratio between the different rock units (Table 1), causing S-waves to be refracted to a different extent than P-waves, result in further complications, and would ideally need to be handled appropriately by any 3-D velocity model, which would need to deal with refractions across dipping boundaries whose strike is oblique to the propagation paths. The essential adjustment required is to take account of the overall WNW-ESE development of a 'faster' seismic velocity structure, which will have the effect of adjusting my revised hypocentre (Fig. 1) away from EVW and HHF and towards AVH and PRH, i.e., adjusting it NW or NNW. In the absence of a 3-D seismic velocity model that takes all the above factors into account, I cannot assign any formal margins of uncertainty to my solution, although I recognize that the stated co-ordinates are likely to be uncertain by hundreds of metres. However, I note (Fig. 1) that the above-mentioned coordinates adjoin the location reported by O'Toole et al. (2013) for the 27 May 2011 event ( $M_{L}$ 1.5), at SD 3780935606 (BNG easting $\pm 28 \mathrm{~m}$; BNG northing $\pm 85 \mathrm{~m}$ ) and depth $2343 \pm 2 \mathrm{~m}$ (as well as the coordinates for both events reported by Galloway, 2012), suggesting that these induced events occurred in close proximity, as others have previously inferred from the similarity of their seismic waveforms recorded by the temporary network of local seismograph stations. A hypocentre south of the borehole, rather than east of it as suggested by Seismik (2012) and Clarke et al. (2014), is also consistent with the geometry of induced fractures expected from the stress field, as already noted.

\section{Figure 5 here: focal mechanism}

As is discussed in more detail in the online supplement, I have determined the focal mechanism of the 2 August 2011 event in a conventional manner using polarities of $\mathrm{P}$ - and S-waves recorded at the temporary local stations. This differs from the approach adopted for this event by Seismik (2012) and Clarke et al. (2014), which utilized both polarities and relative amplitudes of P- and S-waves using a method that was not explained. Although some of the polarities are difficult to read, my preferred focal-mechanism orientation (with strike $030^{\circ}$, dip $75^{\circ}$, and rake $-20^{\circ}$ ) is illustrated in Fig. 5. I have also investigated the 27 May 2011 event, again using P- and S-wave polarities recorded at the temporary stations; no differences relative to the 2 August 2011 focal mechanism could be resolved, supporting the view that the focal mechanisms of both events were the same or very 
similar. This focal mechanism has a similar orientation to that reported by Clarke et al. (2014), assuming the projection and angular definition ambiguities affecting their solution, mentioned above, have indeed been correctly resolved. However, my method, my choice of hypocentral location, which determines the focal sphere projection, and some of my polarity picks, are different from theirs, so the logic underlying my solution is rather different. My solution is also internally consistent, in that my polarity picks can be seen to be consistent with it (Fig. 5) and their timings can be seen to be consistent with the hypocentral location (see the online supplement). My solution has also been presented as a standard projection with the supporting data included (Fig. 5), with all associated angles and polarities expressed in accordance with standard definitions.

The validity of my focal mechanism solution (Fig. 5) of course depends on my hypocentral location being correct, because the latter determines where stations plot on the focal sphere. However, it is apparent from the foregoing discussion and the more detailed discussion in the online supplement that the principal cause of uncertainty in the hypocentre is its true north-south (or NNW-SSE) position along the line between the stations PRH and HHF. If the hypocentre were to be adjusted north of my reported 'preferred' location so it would be moved farther away from HHF and closer to $\mathrm{PRH}$, then PRH would plot at a steeper angle to the vertical in Fig. 5, nearer the centre of this projection on its south side, and HHF would plot at a less steep angle to the vertical, farther away from the centre of this projection to the north. For both S-wave components the same polarity would still be expected, and the dilatational character of the P-waves at HHF would likewise remain expected. The focal mechanism orientation determined in Fig. 5 is thus stable with respect to this aspect of uncertainty in the hypocentral location.

\section{Discussion}

The UK shale gas industry issued guidelines in 2013 regarding the transparency of data for onshore exploration; these guidelines were recently updated (UKOOG, 2015). It is thus considered good practice to disclose technical data derived from any exploration project, as this will benefit future projects. Regulations requiring such disclosure after an initial six-month embargo were subsequently enacted (UK Parliament, 2014); the online platform for publically hosting seismicity data is currently under development (BGS, 2015). Proper documentation of data is also a standard requirement for academic publication, so that others may validate one's conclusions. However, despite the proliferation of consultancy reports and other previous publications, a serious lack of clarity and transparency has prevailed. For example, in accordance with each of these principles, Clarke et al. (2014) should have published, in a standard format, their dataset in full, including digital 
seismograms (and associated metadata such as absolute timing information) and derived data such as arrival time picks, as well as the aforementioned analysis of BHP, plus the reasoning underlying why their own interpretations differed from others. Activist objectors to shale gas in the UK have persistently argued that developers have neither been open with information about their project plans nor have portrayed their activities accurately. In principle, the Clarke et al. (2014) publication, with authorship representing the company responsible for the 2011 Preese Hall project, was most welcome, and might usefully have served as a definitive work of record. Unfortunately, in addition to the evident mistakes and oversights, the unclear presentation of data, methods, and assumptions hampers and/or prevents independent verification of the authors' conclusions, which is especially necessary where these differ from those of other workers who have investigated the same earthquake sequence, and where no explanation for these differences has been provided. This is neither consistent with data transparency nor an appropriate way of working within the scientific community. In the absence of full transparency, I have done my best to resolve the various issues.

\subsection{Physical mechanism of the induced seismicity}

The present reanalysis supports the aforementioned previous deductions that this induced seismicity occurred south of the Preese Hall-1 well. It also supports the view, suggested above, that a plausible candidate mechanism for the induced seismicity is that the fracture networks that developed during several of the fracking stages propagated southward and intersected an ESEdipping normal fault, as depicted schematically in Fig. 1. Following Davies et al. (2013), it might thus be envisaged that some of the fracking fluid leaked from this fracture network into this fault, thereby increasing the fluid pressure within the fault and thus reducing its effective normal stress, thus bringing it to the condition for shear failure. As Westaway (in press) has noted, after Davies et al. (2013), the 10 hour delay between injection and each of the two largest induced events, on 1 April 2011 (following fracking stage 2) and on 27 May 2011 (following stage 4) might in principle relate either to properties of the fault (e.g., storage and transmissibility characteristics) or to properties of the adjoining rock mass (e.g., poroelasticity, or the time required for the transmission of fluid pressure by pressure diffusion).

However, as already noted, the state of stress will also change in the surroundings to these induced fracture networks, as a result of their component of dilatational strain. In this case, given the geometry envisaged in Fig. 1, with the fault and fracture network oblique and with the former approaching the end of the latter, based on previous experience (e.g., Westaway, 2002, 2006) it can be envisaged that the opening of the fracture network will increase the component of right-lateral 
shear stress across the fault (itself conducive to 'unclamping' the fault, but favouring the opposite sense of slip to that observed; Fig. 5) but will also increase the normal stress across the fault (itself conducive to 'clamping' the fault). The upward convergence between the fault and the fractures would also mean that the opening of the latter would induce a sense of vertical shear on the former that would be conducive to a component of reverse slip, the opposite to that observed (Fig. 5). It is concluded that the direct effect of fracture dilatation on the stress field cannot account for the observed seismicity; hence the need to consider candidate physical mechanisms involving fluid flow.

As regards the geometry envisaged by Clarke et al. (2014), the same issues would preclude the direct effect of fracture opening as a cause of the observed seismicity. It is also difficult to see how any plausible geometry of fluid flow could cause an earthquake to nucleate at the hypocentre that they favour (Figs 1 and 4), east of and deeper than the Preese Hall-1 well. With this geometry, any faultfracture intersection would have to be above the well track (as viewed in cross-section in Fig. 4). The fluid would then have to flow upward to this point, then downward along the fault plane for many hundreds of metres to nucleate an earthquake at the required depth; the geometry, of induced seismicity east of the well track would indeed lend itself to hypocentres shallower than, rather than deeper than, the well perforations where the fractures initiated. The 2930 m nucleation depth envisaged by Clarke et al. (2014) indeed exceeds the perforation depth for fracking stage 2 (Figs 2(a), 4) by $>300 \mathrm{~m}$, which would require the pressure of the fracking fluid during this stage to have exceeded the threshold to initiate fracture development at this perforation depth by $\sim 3 \mathrm{MPa}$. However, as already discussed, the pressures used in this and other fracking stages are subject to considerable uncertainty. Thus, at this stage, however unlikely it may seem, the deep hypocentre envisaged by Clarke et al. (2014) cannot be formally excluded. This example indeed illustrates the value of reliable calculations of fracking fluid pressure (BHP) for understanding the geomechanics.

\subsection{Issues relating to differential stress}

The high differential stress and orientation of the principal stresses, already noted, mean that the resolved shear stress on any steep fault striking NE-SW in the present study locality will be high (conducive to left-lateral slip), such that increases in fluid pressure associated with fracking may well bring faults with this orientation to the condition for slip, involving reactivation in a left-lateral sense (Fig. 6). Conversely, any steep fault striking NW-SE would be favourably oriented for right-lateral reactivation. This situation is rather different from the innocuous consequences of induced fractures intersecting natural fractures in some U.S. shale gas provinces, such as in the Barnett Shale of Texas (e.g., Gale et al., 2007), where the horizontal stresses are similar in magnitude, and where induced 
earthquakes strong enough to be felt are unknown. As others (e.g., King et al., 2008; Wikel, 2011) have also noted, this similarity in horizontal stresses impacts on the geometry of induced microseismicity when wells are fracked: if the differential stress is high, hypocentres tend to align as discrete planar fractures open in the plane perpendicular to the minimum principal stress; whereas if it is low one tends to observe diffuse clouds of microearthquakes as some hypocentres align along fractures that open in the plane perpendicular to the present-day minimum principal stress, whereas others mark the opening of pre-existing fractures at other orientations (see, also, Gale et al., 2007). From the point of view of the shale developer, the response observed in the Barnett Shale, creating many interconnecting fractures of different orientations, is beneficial to production, a benefit that cannot be anticipated elsewhere. Wikel (2011) indeed noted that, as the Barnett Shale was the first shale gas play to be developed on a large scale, it has served as an analogue for other shale plays; however, in view of the radically different state of stress elsewhere, this analogy is not always appropriate. Wikel (2011) has indeed argued that other shale plays, including the Bakken (Williston Basin; Montana, North Dakota, Saskatchewan and Manitoba), Cardium (Alberta and British Columbia), Horn River (British Columbia), Marcellus (Appalachian Basin; New York, Pennsylvania, Ohio, Maryland and West Virginia, and surroundings), Monterey (California), and Montney (Alberta and British Columbia) are likewise subject to significant horizontal stress anisotropy, a list to which I would add the Bowland Shale (Fig. 2(b); see also below).

\section{Figure 6 here: Mohr Circle diagram}

Although many felt induced earthquakes have occurred in the USA, the largest above magnitude 5, they are associated with subsurface disposal of wastewater (which is illegal in the UK and throughout the European Union) or hydraulic fracturing of relatively permeable rocks to enhance recovery of conventional hydrocarbons (e.g., McGarr, 2014; Westaway, in press). Nonetheless, the first felt event associated with fracking (of the Ordovician Utica Shale beneath the more familiar Devonian Marcellus Shale) for shale gas and large enough to be felt, occurred recently, the $M_{L} 3.0$ Poland Township event of 10 March 2014 in NE Ohio (Skoumal et al., 2015). However, some months earlier, in Harrison County, eastern Ohio, a similar fracking project (in Ordovician shale of the Point Pleasant Formation) also resulted in a sequence of induced earthquakes, the largest of which ( $M_{W}$ 2.2; on 5 October 2013) might well have been felt, given its size (Westaway and Younger, 2014), but was not (Friberg et al., 2014). An indication of the state of stress in this part of the USA is provided by in situ measurements at Norton Mine, a former limestone mine at $\sim 2200 \mathrm{ft}$ or $\sim 670 \mathrm{~m}$ depth, which is being assessed as a future compressed air energy storage facility. Bauer et al. (2005) 
reported recent measurements of $\sigma_{1}(\mathrm{E}-\mathrm{W}) 5330 \mathrm{psi}$ or $36.7 \mathrm{MPa}, \sigma_{2}(\mathrm{~N}-\mathrm{S}) 4100 \mathrm{psi}$ or $28.2 \mathrm{MPa}$, and $\sigma_{3}$ (vertical) $3270 \mathrm{psi}$ or $22.5 \mathrm{MPa}$, as well as compilations of historical and recent measurements indicating $\sigma_{1} 6110 \mathrm{psi}$ or $42.1 \mathrm{MPa}, \sigma_{2} 3630 \mathrm{psi}$ or $25.0 \mathrm{MPa}$, and $\sigma_{3} 3030 \mathrm{psi}$ or $20.9 \mathrm{MPa}$. High differential stress is thus indicated in this part of Ohio, which would be expected to increase further when extrapolated to the depths of the fracking $(>2 \mathrm{~km})$. This particular dataset might be regarded as problematic given that the vertical stress values are much larger than expected from the loading effect of the overburden; however, in this formerly glaciated region, the possibility exists that the vertical stress has not re-equilibrated following removal of the former ice load (cf. Evans et al, 1982, 1989). Furthermore, the E-W orientation of the maximum principal stress determined in modern measurements is consistent with the design of this mine (Bauer et al., 2005), indicating that the mining activity has not perturbed the orientation of the stress field.

Other measurements of high differential stress have also been made in the Appalachian region of the USA, as have been reported, for example, by Engelder (1993). Thus, for example, at Auburn, New York, Hickman et al. (1985) reported for a depth of $1482 \mathrm{~m}$ maximum and minimum horizontal stresses of $49.0 \pm 2.0$ and $30.6 \pm 0.4 \mathrm{MPa}$ and a vertical stress of $37.9 \mathrm{MPa}$. In this locality the maximum principal stress was reported as oriented $\mathrm{N} 83 \pm 15^{\circ} \mathrm{E}-\mathrm{S} 83 \pm 15^{\circ} \mathrm{W}$, the differential stress at the stated depth being 18.6 MPa. At South Canisteo, New York, at $1000 \mathrm{~m}$ depth in the Wilkins Well, Evans et al. (1989) reported maximum and minimum horizontal stresses of $\sim 38$ and $\sim 20 \mathrm{MPa}$ and a vertical stress of $\sim 26 \mathrm{MPa}$. In this locality the maximum principal stress was reported as oriented N68.5 $\pm 24^{\circ} \mathrm{E}-\mathrm{S} 68.5 \pm 24^{\circ} \mathrm{W}$, the differential stress at the stated depth being $\sim 18 \mathrm{MPa}$. In each of these cases it can be expected that, extrapolated to a depth of $\sim 2.5 \mathrm{~km}$, the differential stress will be at least as high as the 30 MPa value at Preese Hall (Fig. 2(b)); hence, from the point of view of exploring any cause-and-effect connection between high differential stress and felt induced seismicity, the Appalachian region of the USA is a suitable analogue for the Bowland Shale.

As another example, the largest earthquake generally accepted as having been induced by fracking for shale gas occurred on 19 May 2011 in the Horn River Basin, near the town of Fort Nelson in NE British Columbia, Canada; this was recently assessed by Westaway and Younger (2014) as an indication of the 'worst case scenario' of an induced earthquake that might occur as a result of fracking in the UK. This event had $M_{\llcorner} 3.8$ and was felt but caused no damage (BGOGC, 2012); it was considered equivalent to $M_{w} 3.6$ by Ellsworth (2013). This event, and many others in the same locality, in the magnitude $\sim 2$ to $\sim 3$ range, likewise occurred in a formation at relatively high differential stress (Roche et al., 2015). 
Conversely, the differential stress is very low in the Barnett Shale shale gas province in Texas (e.g., Gale et al., 2007; Wikel, 2011), where - notwithstanding the $>15000$ shale gas wells that have been drilled and fracked - no instance of felt induced seismicity has occurred. Nonetheless, induced earthquakes, albeit unrelated to shale gas production, large enough to be felt have occurred in the vicinity. The largest of these to date, the $M_{L}$ 3.6 Azle, Texas, event of 8 December 2013, occurred in Precambrian basement beneath the local Palaeozoic sedimentary sequence (Hornbach et al., 2015). According to Hornbach et al. (2015), this population of induced earthquakes was caused by injection of industrial wastewater into the Ellenberger Formation, consisting of highly permeable, karstified, Ordovician limestone (e.g., Loucks, 2006); in the view of these authors, some of this water leaked from this sediment into the underlying basement, where it facilitated reactivation of an ancient normal fault to a depth of $\sim 8 \mathrm{~km}$. A potential difficulty with this interpretation concerns the geometry (illustrated in Fig. 2 of Hornbach et al., 2015), the water load arising from this instance of wastewater injection having been concentrated over the hanging-wall of the basement normal fault, which has slipped in the induced seismicity in a normal sense. Since this basement normal fault is very steep (dip $\sim 70^{\circ}$ ), from previous experience (e.g., Westaway, 2002,2006 ) the main effect of this load will be to increase the shear stress (in the sense conducive to normal faulting) across this fault, thus unclamping it. If this is the correct explanation for this instance of induced seismicity, a very simple mitigation measure is feasible, namely to switch the wastewater injection to the footwall and/or to balance it in future on both sides of the fault so no differential loading effect, which would act to unclamp the fault, can develop. Clearly, if, instead, Hornbach et al. (2015) have identified the correct explanation, then this would not work as a mitigation measure; however, the possibility seems worthy of consideration. Regardless of the correct explanation, it is evident that in this region the differential stress is much greater in the basement than at shallower $(\sim 2 \mathrm{~km})$ depths in the Barnett Shale, as is to be expected from the increase in differential stress with depth that typifies most regions.

The above-mentioned Azle example has a number of implications for the UK. The first is the clear need to uniquely identify the causal mechanism for the induced seismicity, since this bears upon potential mitigation strategies. Second, given the possibility that the Hornbach et al. (2015) explanation is correct, it highlights the importance, from the point of view of mitigating induced seismicity, of ensuring for any UK shale gas developments that fracking fluid is contained within the shale layers being 'fracked' and not allowed to leak into underlying more permeable sediments and thence into basement. Third, given the possibility that my alternative explanation is correct, the 
potential significance of this 'dry' causal mechanism warrants recognition (cf. Davies et al., 2013); just because this mechanism did not contribute to the Preese Hall induced seismicity in 2011 (see above; section 5.1) does not mean that in another locality in northern England, where the geometry of pre-existing faults and induced fractures is different, it can also be excluded as a causal factor.

A further issue concerns the state of stress at Preese Hall. Following Zoback and Healy (1984), many U.S. analyses of induced seismicity have considered the concept of an idealized 'Zoback-Healy stress state' in relation to the standard Mohr-Coulomb criterion for fault slip. It is evident, however, that the Preese Hall induced seismicity does not represent such an idealized state. This is most clearly apparent because under this state of stress the intermediate principal stress $\sigma_{2}$ would be oriented along the fault plane, which is clearly not so since $\sigma_{2}$ is vertical (Fig. 2(b)) and the fault plane dips at $75^{\circ}$ (Fig. 5). Reasons why this idealized theoretical approach breaks down in this instance include, first, the fact that the present-day stress field, conducive to strike-slip (Figs. 2(b) and 5), is very different from the extensional stress field when the rocks were laid down during the Carboniferous period. Second, unlike more recent variants, such as those developed through my own work (e.g., Westaway, 2002, 2006), this theory does not take account of the fact that the rocks bounding a fault will have nonzero cohesion, making it mechanically easier for a fault that is not optimally aligned with respect to the stress field to slip, rather than for a new fault to form at an optimal orientation.

As a final point pertaining to differential stress, Roche et al. (2015) have noted a correlation between the state of stress and the size distribution for the resulting earthquakes induced by fracking in different shale formations in the Horn River region. Size distributions of earthquakes are typically characterized by 'b-values', where $-b$ is the gradient of a logarithmic plot of the cumulative frequency of occurrence, $\mathrm{N}$, of the earthquakes in a given region, during a given span of time, which are above magnitude $M$ (i.e., $\left.b=-d \log _{10}(N) / d M\right)$. Populations of earthquakes induced by fracking often have high b-values, $2-3$, so their frequency of occurrence tails off abruptly above a particular size threshold that is often at quite a small magnitude; in contrast, naturally-occurring earthquake populations typically have $b \sim 1$. However, Roche et al. (2015) showed that $b$-values for different populations of induced earthquakes in NW Canada are inversely correlated with the local differential stress, with $b \sim 1$ in the localities with the highest differential stress. Decades earlier, Scholz (1968) showed that laboratory rock-mechanics experiments demonstrate a negative correlation between differential stress and b-values, and suggested that variability in differential stress is thus the main cause of variability in b-values between different earthquake populations. It now seems evident that this deduction is of the utmost significance for populations of earthquakes induced by fracking; in 
regions of high differential stress, including the examples just discussed, $b$-values can be expected to be low and populations of induced earthquakes can thus be expected to extend across more of the magnitude range, thus giving rise to a significantly higher probability of occurrence of events that are large enough to be felt. The Preese Hall induced population evidently fits this general pattern, given the evidence of high local differential stress, although the absence of systematic microseismic monitoring makes it impossible to confirm directly that the $b$-value for this earthquake population was indeed relatively low. It follows, however, that it will not be possible, as part of monitoring any future UK shale gas industry, to use b-values to discriminate between populations of 'natural' and induced earthquakes, since both can be expected to have b-values of $\sim 1$.

\subsection{Lessons learned}

It is worth considering how the induced seismicity nuisance arising from the Preese Hall fracking might have been mitigated and how the uncertainties in the resulting dataset might have been reduced. It goes without saying that microseismic monitoring should have been in place to record all induced seismicity resulting from the Preese Hall fracking. The same seismograph network should also have been in place to record all the explosive shots used to perforate the borehole casing (the first of which took place on 4 March 2011 according to de Pater and Baisch, 2011). This would have improved constraint on the local seismic velocity structure (identified above, in section 4, as a continuing source of uncertainty), and would also have meant that the subsequent induced earthquakes could have been located relative to these perforation shots, mitigating the location difficulties that have arisen due to the complex seismic velocity structure. However, this was not a UK regulatory requirement at the time, and in other instances (such as for the Horn River induced seismicity a few months later; BCOGC, 2012) local seismograph networks were likewise only installed after induced seismicity had occurred.

Second, since it was already well known in 2011 that induced earthquakes associated with shearing on faults in a given locality all have very similar focal mechanisms, it should have been apparent once the induced seismicity started that the limited number of seismographs available could have been put to best use by re-siting them after intervals of time, so as to gradually build up coverage of the focal sphere to enable a composite focal mechanism to be constrained as well as possible, this being a standard strategy in earthquake seismology (e.g., Pytharouli et al., 2011).

Third, the subdivision of the analysis among multiple consultancy organizations led to data being analysed in a fragmentary manner, with no overall integration nor, indeed, checking of results for 
obvious mistakes (such incorrect plotting of focal mechanisms) evident. Analysis should include checking for consistency between datasets, since different datasets sample different aspects of the geology. For example, careful (re)analysis of high-resolution background microseismicity data might reveal locations of potential planes of weakness (especially in a locality where the state of stress is so close to criticality even before fracking takes place; cf. Fig. 6), which can then be avoided when fracking subsequently takes place. If datasets are seen to be inconsistent (e.g., stress field orientation data from a borehole appear inconsistent with microseismicity data; or determinations of the maximum principal stress direction by different consultants are inconsistent with one another; or a newly-acquired 3-D seismic reflection dataset is inconsistent with older 2-D seismic sections), there may well be significant features in the local geology that are not being accounted for. Rather than reporting data in isolation, it should be considered as regards consistency in relation to potential conceptual models. However, multiple conceptual models should be considered, rather than over-analyzing a single model built from sparse data; it is 'better to be approximately right than precisely wrong' (Bond et al., 2012).

Finally, the inherent variability of fault and fracture systems means that data pooling from multiple sites may well be beneficial to the objective of reducing geological uncertainty (e.g., Lunn et al., 2008). For instance, data from multiple sites can place bounds on the uncertainty in bulk fault parameters, such as fault length and thickness. The example of this principle, whereby experience of induced seismicity from fracking in other regions of high differential stress, such as Ohio and British Columbia, may guide expectations in the UK, has already been discussed, although it should be noted that from other points of view (such as rheological properties of the shale) other localities might serve as better UK analogues (cf. Westaway and Younger, 2014).

The fact that the Carboniferous sediments in northern England are pervasively faulted and fractured (e.g., British Coal Corporation, 1997; Kirby et al., 2000; Pharaoh et al., 2011) and many of these faults are favourably oriented relative to the present-day stress field to slip in induced earthquakes associated with fracking (cf. Fig. 6) warrants wider recognition as an aspect of UK shale gas plays that falls outside the scope of much U.S. experience. I therefore disagree with the conclusion of de Pater and Baisch (2011) that the 2011 occurrence of 'nuisance' (i.e., felt) induced seismicity was the result of such a unique combination of conditions that the probability of recurrence is very low (they estimated this probability as $\sim 0.0001$ for each future shale gas well) and consider that this possibility must be planned for by any future UK shale gas industry. Avoidance of routine occurrence of 'nuisance' induced seismicity will require the avoidance of all faults with dimensions of hundreds of 
metres (Westaway and Younger, 2014). The aforementioned discrepancies between interpretations of seismic sections cast doubt on whether this is currently feasible (cf. Bond et al., 2007a,b, 2012), whereas consideration of the many faults already known would mean excluding much of the volume of the shale resource. Conversely, mitigation of this nuisance by suspending fluid injection when the fluid reaches any fault will require the development of real-time control systems, which currently do not exist, possibly by integrating real-time monitoring of smaller-scale induced seismicity with realtime monitoring of fluid pressure. In the absence of such technology, the choice would seem to be between tolerating occasional occurrences of this form of nuisance or not developing shale gas in the UK.

\section{Conclusions}

The best-recorded microearthquake in the 2011 Preese Hall sequence, at 08:12 on 2 August 2011, had a focal depth of $2.5 \mathrm{~km}$, beneath a preferred epicentre at BNG reference SD 377 358, some hundreds of metres south of the Preese Hall-1 wellhead. My preferred focal mechanism for this event has strike $030^{\circ}$, dip $75^{\circ}$, and rake $-20^{\circ}$; this NNE-striking nodal plane, apparently formed by a normal fault of Early Carboniferous age, is inferred to have been the fault plane, reactivated in a mainly left-lateral sense. The other induced earthquakes in the sequence are inferred to have occurred in close proximity and to have had similar focal mechanisms. This locality exhibits high differential stress, with maximum and minimum principal stresses roughly north-south and eastwest. This stress field is favourably oriented to reactivate steep faults striking NNE-SSW or NE-SW in a left-lateral sense; southward leakage of fracking fluid into one such fault evidently caused the induced seismicity. This instance of induced seismicity is consistent with an emerging pattern of occurrences of induced earthquakes large enough to be felt (sometimes with $M>3$ ), when fracking for shale gas in regions of high differential stress. Such occurrences, involving earthquake populations that tail off gradually towards such magnitudes (with relatively low b-values) are indeed consistent with expectations in regions of high differential stress. The combination of pervasive faulting, which is difficult to resolve using seismic reflection, and high differential stress, facilitating reactivation of these faults large enough to cause felt earthquakes when they slip, poses a significant technical challenge for any future UK shale gas industry.

\section{Acknowledgments}

Digital seismograms recorded by temporary and permanent seismograph stations operated by the British Geological Survey are available to registered users for free download in the standard MiniSEED format at ftp://ftp.nmh.ac.uk/gsrg/PreeseHallData. Other data used in this study are 
available from the sources noted in the reference list. However, in many cases only subsets of derived data are included in these sources, the underlying raw data having not been placed in the public domain. I thank Terry Engelder and an anonymous reviewer for their thoughtful and constructive comments.

\section{References}

Baker Hughes, 2011. Wellbore failure analysis and geomechanical modelling in the Bowland Shales, Blackpool, UK: preliminary technical report. Baker Hughes Incorporated, Houston, Texas, 53 pp. Available online: http://www.cuadrillaresources.com/wp-

content/uploads/2012/02/Geomechanical-Study-Appendix-1-2.11.2011.pdf (accessed 10 May 2015)

Baptie, B., 2010. Seismogenesis and state of stress in the UK. Tectonophysics, 482, 150-159.

Bauer, S.J., Munson, D.E., Hardy, M.P., Barrix, J., McGunegle, B., 2005. In situ stress measurements and their implications in a deep Ohio mine. In: Proceedings of Alaska Rocks 2005, the 40th U.S. Symposium on Rock Mechanics, Anchorage, Alaska, 25-29 June 2005. American Rock Mechanics Association paper ARMA-05-804. Available online: https://www.onepetro.org/conferencepaper/ARMA-05-804 (accessed 12 May 2015)

BCOGC, 2012. Investigation of observed seismicity in the Horn River Basin. British Columbia Oil and Gas Commission, Fort St John, British Columbia, Canada, 29 pp. Available online: http://www.bcogc.ca/node/8046/download?documentID=1270 (accessed 3 January 2014)

BGS, 2015. Monitoring and testing future energy in the UK. Available online: http://www.bgs.ac.uk/research/energy/shaleGas/esios.html (accessed 7 March 2015)

Bond, C.E., Gibbs, A.D., Shipton, Z.K., Jones, S., 2007a. What do you think this is? “Conceptual uncertainty" in geoscience interpretation. GSA Today, 17 (10), 4-10.

Bond C.E., Shipton, Z.K., Butler, R.W.H., Jones, R.J., Gibbs, A.D., 2007b. Knowledge transfer in a digital world: uncertainty, visualisation and data management. Geosphere, 3, 568-576.

Bond, C.E., Lunn, R.J., Shipton, Z.K., Lunn, A.D., 2012. What makes an expert effective at interpreting seismic images? Geology, 40, 75-78.

Bradshaw, G.A., Zoback, M.D., 1988. Listric normal faulting, stress refraction, and the state of stress in the Gulf Coast basin. Geology, 16, 271-274.

Brenner, S.L., Gudmundsson, A., 2004. Arrest and aperture variation of hydrofractures in layered reservoirs. In: Cosgrove, J.W., Engelder, T. (eds), The Initiation, Propagation, and Arrest of Joints and Other Fractures. Geological Society, London, Special Publications, 231, 117-128. 
British Coal Corporation, 1997. Three-dimensional seismic surveying to investigate the geological structure of shear zones within the Selby coalfield. European Union, Directorate-General Energy, report EUR 17161 EN. Office for Official Publications of the European Communities, Luxembourg, $122 \mathrm{pp}$.

Cartwright, P.B., 1997. A review of recent in-situ stress measurements in United Kingdom Coal Measures strata. In: Sugawara, K., Obara, Y., eds, Rock Stress: Proceedings of the International Symposium on Rock Stress, Kumamoto, Japan, 7-10 October 1997. Balkema, Rotterdam, pp. 469474.

Chopra, S., Castagna, J., Portniaguine, O., 2006. Seismic resolution and thin-bed reflectivity inversion. Canadian Society for Exploration Geophysics Recorder, January 2006, 19-25.

Clarke, H., Eisner, L., Styles, P., Turner, P., 2014. Felt seismicity associated with shale gas hydraulic fracturing: The first documented example in Europe. Geophysical Research Letters, 41, 83088314.

Cuadrilla, 2014a. Temporary Shale Gas Exploration; Preston New Road, Lancashire; Environmental Statement, Appendix L - Induced Seismicity. Cuadrilla Bowland Ltd., Lichfield, 140 pp. Available online: http://planningregister.lancashire.gov.uk/Attachments/6586/PNR ES Vol2 Appndx $\underline{L}$ Induced Seismicity.pdf (accessed 9 March 2015)

Cuadrilla, 2014b. Temporary Shale Gas Exploration; Roseacre Wood, Lancashire; Environmental Statement, Appendix L - Induced Seismicity. Cuadrilla Elswick Ltd., Lichfield, 140 pp. Available online: http://planningregister.lancashire.gov.uk/Attachments/6591/RW ES Vol2 Appndx $\underline{L}$ Induced Seismicity.pdf (accessed 9 March 2015)

Davies, R., Foulger, G., Bindley, A., Styles, P., 2013. Induced seismicity and hydraulic fracturing for the recovery of hydrocarbons. Marine and Petroleum Geology, 45, 171-185.

Davis, P.M., 1983. Surface deformation associated with a dipping hydrofracture. Journal of Geophysical Research, 88, 5826-5834.

de Pater, C.J., Baisch, S., 2011. Geomechanical study of Bowland Shale seismicity: synthesis report. Cuadrilla Resources Ltd., Lichfield, 71 pp. Available online: http://www.rijksoverheid.nl/bestanden/documenten-enpublicaties/rapporten/2011/11/04/rapport-geomechanical-study-of-bowland-shaleseismicity/rapport-geomechanical-study-of-bowland-shale-seismicity.pdf (accessed 5 April 2015) Eisner, L., Janská, E., Opršal, I., Matoušek, P., 2011. Final Report: Seismic analysis of the events in the vicinity of the Preese Hall well. Seismik s.r.o., Prague, Czech Republic, 29 pp. Available online: http://www.cuadrillaresources.com/wp-content/uploads/2012/02/Geomechanical-StudyAppendix-3-2.11.2011.pdf (accessed 8 March 2015) 
Eisner, L., Williams-Stroud, S., Hill, A., Duncan, P., Thornton, M., 2010. Beyond the dots in the box: Microseismicity-constrained fracture models for reservoir simulation. The Leading Edge, 29, 326333.

Ellsworth, W.L., 2013. Injection-induced earthquakes. Science, 341, 8 pp., doi: 10.1126/science.1225942

Engelder, T., 1993, Stress Regimes in the Lithosphere. Princeton University Press, Princeton, New Jersey, $457 \mathrm{pp}$.

Evans, C.J., Brereton, N.R., 1990. In situ crustal stress in the United Kingdom from borehole breakouts. In: Hurst, A., Lovell, M.A., Morton, A.C. (eds), Geological Applications of Wireline Logs. Geological Society, London, Special Publications, 48, 327-338.

Evans, K.F., 1989. Appalachian stress study; 3, Regional scale stress variations and their relation to structure and contemporary tectonics. Journal of Geophysical Research, 94, 17,619-17,645.

Evans, K.F., Engelder, T., Plumb, R.A., 1989. Appalachian stress study; 1, A detailed description of in situ stress variations in Devonian shales of the Appalachian Plateau. Journal of Geophysical Research, 94, 7129-7154.

Evans, K.F., Holzhausen, G., Wood, D., 1982. The geometry of a large-scale nitrogen gas hydraulic fracture formed in Devonian shale: An example of fracture mapping with tiltmeters. Society of Petroleum Engineers Journal, 22, 755-763.

Fisher, K., Warpinski, N., 2012. Hydraulic-fracture-height growth: Real data. Society of Petroleum Engineers, Productions and Operations Journal, 27, 8-19.

Freeman, T., 2015. Moratorium on fracking in Scotland. Available online:

https://www.holyrood.com/articles/news/moratorium-fracking-scotland (accessed 10 March 2015)

Friberg, P.A. Besana-Ostman, G.M., Dricker, I., 2014. Characterization of an earthquake sequence triggered by hydraulic fracturing in Harrison County, Ohio. Seismological Research Letters, 85, 1295-1307.

Gale, J.F.W., Reed, R.M., Holder, J., 2007. Natural fractures in the Barnett Shale and their importance for hydraulic fracture treatments. AAPG Bulletin, 91, 603-622.

Galloway, D.D., 2012. Bulletin of British Earthquakes 2011. British Geological Survey Internal Report, OR/12/041. British Geological Survey, Edinburgh, 46 pp. Available online: http://www.earthquakes.bgs.ac.uk/publications/bulletins/Eqbull2011.pdf (accessed 8 March 2015)

Geiser, P., Lacazette, A., Vermilye, J., 2012. Beyond "dots in a box": an empirical view of reservoir permeability with tomographic fracture imaging. First Break, 30, 63-69. 
Geiser, P., Leary, P., 2014. Tomographic Fracture Imaging (TFI): Direct 5D mapping of transmissive fracture/fault zones using seismic emission tomography (SET). In: Proceedings, Thirty-Ninth Workshop on Geothermal Reservoir Engineering, Stanford University, Stanford, California, 24-26 February 2014. Paper SGP-TR-202, 6 pp. Available online:

https://pangea.stanford.edu/ERE/pdf/IGAstandard/SGW/2014/Geiser.pdf (accessed 13 November 2015)

GFZ, 2015. Download the World Stress Map database Release 2008. http://dc-app3-14.gfzpotsdam.de/pub/stress data/stress data frame.html (accessed 10 May 2015)

Green, C.A., Styles, P., Baptie, B.J., 2012. Preese Hall shale gas fracturing: review \& recommendations for induced seismic mitigation. UK Government Department of Energy and Climate Change, London, 26 pp. Available online: https://www.gov.uk/government/uploads/system/uploads/attachment_data/file/48330/5055preese-hall-shale-gas-fracturing-review-and-recomm.pdf (accessed 8 March 2015)

Harper, T.R., 2011. Well Preese Hall-1: The mechanism of induced seismicity. Geosphere Ltd., Beaworthy, Devon, 67 pp. Available online: http://www.cuadrillaresources.com/wpcontent/uploads/2012/06/Geosphere-Final-Report.pdf (accessed 9 March 2015)

Heidbach, O., Tingay, M., Barth, A., Reinecker, J., Kurfeß, D., Müller, B., 2010. Global crustal stress pattern based on the World Stress Map database release 2008. Tectonophysics, 482, 3-15.

Hickman, S.H., Healy, J.H., Zoback, M.D., 1985. In situ stress, natural fracture distribution and borehole elongation in the Auburn geothermal well, Auburn, New York. Journal of Geophysical Research, 90, 5497-5512.

Hornbach, M.J., DeShon, H.R., Ellsworth, W.L., Stump, B.W., Hayward, C., Frohlich, C., Oldham, H.R., Olson, J.E., Magnani, M.B., Brokaw, C., Luetgert, J.H., 2015. Causal factors for seismicity near Azle, Texas. Nature Communications, 7728,11 pp. doi: 10.1038/ncomms7728

King, G.E., Haile, L., Shuss, J., Dobkins, T.A., 2008. Increasing fracture path complexity and controlling downward fracture growth in the Barnett shale. Presented at the 2008 SPE Shale Gas Production Conference, Fort Worth, Texas, 16-18 November 2008. SPE paper 119896.

Kirby, G.A., Baily, H.E., Chadwick, R.A., Evans, D.J., Holliday, D.W., Holloway, S., Hulbert, A.G., Pharaoh, T.C., Smith, N.J.P., Aitkenhead, N., Birch, B., 2000. The structure and evolution of the Craven Basin and adjacent areas. Subsurface Memoir. The Stationery Office, London, 130 pp. Klose, C.D., 2007a. Geomechanical modeling of the nucleation process of Australia's 1989 M5.6 Newcastle earthquake. Earth and Planetary Science Letters, 256, 547-553.

Klose, C.D., 2007b. Mine water discharge and flooding: A cause of severe earthquakes. Mine Water and the Environment, 26, 172-180. 
Klose, C.D., 2013. Mechanical and statistical evidence of the causality of human-made mass shifts on the Earth's upper crust and the occurrence of earthquakes. Journal of Seismology, 17, 109-135.

Lacazette, A., Vermilye, J., Fereja, S., Sicking, C., 2013. Ambient fracture imaging: a new passive seismic method. In: Proceedings, SPE, SEG, and AAPG Unconventional Resources Technology Conference, Denver, Colorado, 12-14 August 2013. Paper URTeC 1582380, 10 pp. Available online: http://www.terrexseismic.com/media/20473/ambient fracture imaging.pdf (accessed 13 November 2015)

Lindsay, M.D., Jessell, M.W., Ailleres, L., Perrouty, S., de Kemp, E., Betts, P.G., 2013. Geodiversity: Exploration of 3D geological model space. Tectonophysics 594, 27-37.

Lunn, R.J., Shipton, Z.K., Bright, A.M., 2008. How can we improve estimates of bulk fault zone hydraulic properties? In: The Internal Structure of Fault Zones: Implications for Mechanical and Fluid-Flow Properties, C.A.J. Wibberley, W. Kurz, J. Imber, R.E. Holdsworth, and C. Collettini, eds., Geological Society, London, Special Publications, 299, 231-237.

Loucks, R.G., 2006. Review of the Lower Ordovician Ellenburger Group of the Permian Basin, West Texas. The University of Texas at Austin, Bureau of Economic Geology, contract report prepared for U.S. Department of Energy West Texas Study, 92 pp. Available online:

http://www.beg.utexas.edu/resprog/permianbasin/PBGSP members/writ synth/Ellenburger\%2 Oreport.pdf (accessed 12 May 2015)

McClure, M.W., 2015. Generation of large postinjection-induced seismic events by backflow from dead-end faults and fractures. Geophysical Research Letters, 42, 8 pp., doi: 10.1002/2015GL065028.

McGarr, A., 2014. Maximum magnitude earthquakes induced by fluid injection, J. Geophys. Res. Solid Earth, 119, 1008-1019.

McGarr, A., Simpson, D., Seeber, L., 2002. Case histories of induced and triggered seismicity. International Handbook of Earthquake and Engineering Seismology, 81A, 647-661.

Mair, R., Bickle, M., Goodman, D., Roberts, J., Selley, R., Shipton, Z., Thomas, H., Younger, P., 2012. Shale gas extraction in the UK: a review of hydraulic fracturing. The Royal Society, London and The Royal Academy of Engineering, London, 76 pp. Available online:

http://royalsociety.org/uploadedFiles/Royal_Society_Content/policy/projects/shale-gas/201206-28-Shale-gas.pdf (accessed 9 March 2015)

Masters, C., Shipton, Z., Gatliff, R., Haszeldine, R.S., Sorbie, K., Stuart, F., Waldron, S., Younger, P.L., Curran, J., 2014. Independent Expert Scientific Panel - Report on Unconventional Oil and Gas. Scottish Government, Edinburgh, 102 pp. Available online: http://www.scotland.gov.uk/Resource/0045/00456579.pdf (accessed 27 March 2015) 
O'Toole, T., Verdon, J.P., Woodhouse, J.H., Kendall, J.M., 2013. Induced seismicity at Preese Hall, UK-A review. 75th EAGE Conference and Exhibition incorporating SPE EUROPEC 2013, London. Extended abstract, 5 pp, doi: 10.3997/2214-4609.20130011. Available online: http://www.earthdoc.org/publication/publicationdetails/?publication=68869 (accessed 27 March 2015)

Pharaoh, T.C., Vincent, C.J., Bentham, M.S., Hulbert, A.G., Waters, C.N., Smith, N.J.P., 2011. The structure and evolution of the East Midlands region of the Pennine Basin. Subsurface Memoir. British Geological Survey, Keyworth, Nottingham, 144 pp.

Pomeroy, P.W., Simpson, D.W., Sbar, M.L., 1976. Earthquakes triggered by surface quarrying - the Wappingers Falls, New York sequence of June, 1974. Bulletin of the Seismological Society of America, 66, 685-700.

Pytharouli, S.I., Lunn, R.J., Shipton, Z.K., Kirkpatrick, J.D., do Nascimento, A.F., 2011. Microseismicity illuminates open fractures in the shallow crust. Geophysical Research Letters, 38, L02402, 5 pp., doi: 10.1029/2010GL045875.

Roche, V., Grob, M., Eyre, T., Van Der Baan, M., 2015. Statistical characteristics of microseismic events and in-situ stress in the Horn River Basin. In: Proceedings of GeoConvention 2015, Calgary, Canada, 4-8 May 2015, 5 pp. Available online:

http://www.geoconvention.com/uploads/2015abstracts/080 GC2015 Statistical characteristics of microseismic events.pdf (accessed 11 May 2015)

Rubinstein, J.L., Mahani, A.B., 2015. Myths and facts on waste water injection, hydraulic fracturing, enhanced oil recovery, and induced seismicity. Seismological Research Letters, 86, 1060-1067.

Scholz, C.H., 1968. The frequency-magnitude relation of microfracturing in rock and its relation to earthquakes. Bulletin of the Seismological Society of America, 58, 399-415.

Seismik, 2012. Preliminary report to Cuadrilla Resources, 13/01/2012. Seismik s.r.o., Prague, Czech Republic, 45 pp. Available online:

https://www.gov.uk/government/uploads/system/uploads/attachment data/file/15742/5071annex-g.pdf (accessed 8 March 2015)

Simpson, D.W., Negmatullaev, S.K., 1981. Induced seismicity at Nurek reservoir, Tadjikistan, USSR. Bulletin of the Seismological Society of America, 71, 1561-1586.

Skoumal, R.J., Brudzinski, M.R., Currie, B.S., 2015. Earthquakes induced by hydraulic fracturing in Poland Township, Ohio. Bulletin of the Seismological Society of America, 105, 189-197.

UKOOG, 2015. Guidelines for UK Well Operators on Onshore Shale Gas Wells. Issue 2 January 2015. The United Kingdom Onshore Operators' Group, 37 pp. Available online: 
http://www.ukoog.org.uk/images/ukoog/pdfs/ShaleGasWellGuidelinesIssue2.pdf (accessed 7 March 2015)

UK Parliament, 2014. The Petroleum Licensing (Exploration and Production) (Landward Areas)

Regulations 2014. Statutory Instruments 2014, no. 1686, 36 pp. Available online:

http://www.legislation.gov.uk/uksi/2014/1686/pdfs/uksi 20141686 en.pdf (accessed 4 April 2015)

Vasco, D.W., Ferretti, A., 2005. On the use of quasi-static deformation to understand reservoir fluid flow. Geophysics, 70 (4), 013-027.

Vasco, D.W., Wicks, C., Karasaki, K., 2002. Geodetic imaging: High resolution reservoir monitoring using satellite interferometry: Geophysical Journal International, 149, 555-571.

Warpinski, N.R., 1989. Determining the minimum in situ stress from hydraulic fracturing through perforations. International Journal of Rock Mechanics and Mining Sciences \& Geomechanics Abstracts, 26, 523-531.

Westaway, R., 2002. Seasonal seismicity of northern California before the great 1906 earthquake. Pure and Applied Geophysics, 159, 7-62.

Westaway, R., 2006. Investigation of coupling between surface processes and induced flow in the lower continental crust as a cause of intraplate seismicity. Earth Surface Processes and Landforms, 31, 1480-1509.

Westaway, R., in press. Induced Seismicity. In: Environmental and Health Issues in Unconventional Oil and Gas Development, Kaden, D., Rose, T.L., eds. Elsevier, Oxford.

Westaway, R., Younger, P.L., 2014. Quantification of potential macroseismic effects of the induced seismicity that might result from hydraulic fracturing for shale gas exploitation in the UK. Quarterly Journal of Engineering Geology and Hydrogeology, 47, 333-350.

Westaway, R., Younger, P.L., Cornelius, C., 2015. Comment on 'Life cycle environmental impacts of UK shale gas' by L. Stamford and A. Azapagic. Applied Energy, 134, 506-518, 2014. Applied Energy, 148, 489-495.

Widess, M.B., 1973. How thin is a thin bed? Geophysics, 38, 1176-1180.

Wikel, K., 2011. Geomechanics: Bridging the gap from geophysics to engineering in unconventional reservoirs. CSEG Recorder, 36 (5), 36-44.

Wolhart, S.L., Harting, T.A., Dahlem, J.E., Young, T.J., Mayerhofer, M.J., Lolon, E.P., 2006. Hydraulic fracture diagnostics used to optimize development in the Jonah Field. SPE 102528, $12 \mathrm{pp}$. In: Proceedings of the 2006 SPE Annual Technical Conference and Exhibition, San Antonio, Texas, 24-27 September 2006. Available online: https://www.onepetro.org/conference-paper/SPE102528-MS (accessed 11 May 2015) 
Younger, P.L., Westaway, R., 2014. Review of the Inputs of Professor David Smythe in Relation to Planning Applications for Shale Gas Development in Lancashire (Planning Applications LCC/2014/0096 /0097 /0101 and /0102) and Associated Recommendations. Report to Lancashire County Council, 12 pp. +1 p. preface. University of Glasgow; available online: http://eprints.gla.ac.uk/108343/

Zoback, M.D., Healy, J.H., 1984. Friction, faulting and in situ stress. Annales Geophysicae, 2, 689-698. 


\section{Figure captions}

Figure 1. Map of the Preese Hall-1 well and its surroundings, modified after Fig. 1 of Clarke et al. (2014), showing the planform of this deviated well, the temporary seismograph stations used to investigate the 2 August 2011 microearthquake, the resulting epicentral locations, and the positions of the adjacent Thistleton-1 (BGS inventory code SD33NE17; co-ordinates SD 39760 37000) and Elswick-1 (BGS inventory code SD43NW15; co-ordinates SD 4238036965 ) wells and of the crosssections in Figs 3 and 4. The epicentral locations determined by BGS (Galloway, 2012) for the 1 April 2011 and 27 May 2011 events and by O'Toole et al. (2013) for the latter event are also shown. My revised epicentral co-ordinates for the 2 August 2011 event have been drawn with nominal error bars indicating uncertainties of $100 \mathrm{~m}$, except that pointing north has been extended in recognition of the fact (evident for reasons discussed in the text) that this location is subject to significant systematic error and probably lies well north or NNW of the co-ordinates marked. Crosses labelled 1, 2 and 3 mark the points where faults 1-3 in Fig. 3 intersect the line of this seismic section at the top of the Clitheroe Limestone Formation (the dual symbols for faults 1 and 2 mark the footwall and hanging-wall cutoffs). The geometry of the seismogenic fault inferred by Clarke et al. (2014) (Fig. 4) is depicted at a depth of $2930 \mathrm{~m}$; that inferred in the present study is depicted at a depth of $2740 \mathrm{~m}$ (Fig. 4), projected SSW for $500 \mathrm{~m}$ assuming a $\mathrm{N} 30^{\circ} \mathrm{E}-\mathrm{S} 30^{\circ} \mathrm{W}$ strike, and ornamented to indicate both the polarity of the overall fault offset and the inferred sense of coseismic slip in 2011. The induced fractures are depicted as emanating at a $\mathrm{N} 7^{\circ} \mathrm{E}-\mathrm{S} 7^{\circ} \mathrm{W}$ azimuth (see the main text) from a notional point near the bottom of the Preese Hall-1 well. Their length depicted is $\sim 300 \mathrm{~m}$, which is appropriate for the volume of fracking fluid used if they are equidimensional (Westaway and Younger, 2014); they are shown dashed for a further $\sim 300 \mathrm{~m}$, which is plausible if their vertical growth was inhibited by variations in rock-mechanical properties, so they developed longer in the sideways direction instead (see the main text). It is suggested that the probable true location of the induced seismicity is at the intersection of this induced fracture trend with the fault line (from this study), most likely several hundred metres south or SSE of the Preese Hall-1 wellhead. Inset shows location, along with a selection of the permanent seismograph stations (none closer than $\sim 80 \mathrm{~km}$; see Galloway, 2012, for further details) that recorded the largest Preese Hall microearthquake on 1 April 2011 and the sites from which in situ stress measurements are discussed (B, Burton-in-Kendal; S, Sellafield).

Figure 2. (a) Summary stratigraphic column for the Preese Hall-1 well, modified from Fig. 3 of de Pater and Baisch (2011), along with the depths of the perforations for the five frack stages, from Fig. 11 of de Pater and Baisch (2011). Each tick symbol represents a perforated zone across a depth 
range of $9 \mathrm{ft}$ or $\sim 3 \mathrm{~m}$, with a total of 81 perforation shots per frack stage; for further details of the well design, see de Pater and Baisch (2011). Lithological boundaries are depicted at True Vertical Depth (TVD); because the borehole is deviated (Figs. 1 and 4) these depths do not all lie beneath the same point on the Earth's surface. The contact between the Pennine Lower Coal Measures Formation and the base of the Collyhurst Sandstone Formation marks the Variscan Unconformity. Note that the Hodder Mudstone Formation is identified by old names such as the 'Worston Group' or 'Worston unit' in much of the recent literature on this locality. (b) In situ stress measurements as a function of depth in the Preese Hall-1 well. The data depicted are the maximum and minimum horizontal stresses, $\sigma_{1}$ and $\sigma_{3}$, and the intermediate vertical stress $\sigma_{2}$. Modified from Younger and Westaway (2014), based originally on documentation submitted in support of applications for planning permission to develop future shale gas wells in Lancashire (Cuadrilla, 2014a, 2014b). de Pater and Baisch (2011) inferred that pore water pressure is hydrostatic in this vicinity; it thus increases linearly to $\sim 25 \mathrm{MPa}$ at $2500 \mathrm{~m}$ depth. Vertical bars labelled $\mathrm{B}$ and $\mathrm{H}$ denote the depth ranges of the in situ stress measurements (discussed in the text) by Baker Hughes (2011) and Harper (2011), respectively.

Figure 3. Excerpt from an east-west seismic section from seismic line GC83-352, with shot points of standard $12.5 \mathrm{~m}$ spacing, passing $\sim 400 \mathrm{~m}$ north of the Preese Hall-1 well, modified from Fig. 7 of de Pater and Baisch (2011). Projected to this section-line, the Thistleton-1 well is $2134 \mathrm{~m}$ east of the Preese Hall-1 well and $2503 \mathrm{~m}$ west of the Elswick-1 well. Symbols identifying stratigraphic boundaries are keyed to Table 1. Interpreted faults labelled 'Type A' only occur within the Carboniferous sedimentary section whereas the less numerous 'Type B' faults pass upwards across the Variscan Unconformity (at the base of the Collyhurst Sandstone Formation - CS; see Table 1). Two of the 'Type A' faults are labelled 1 and 2 to facilitate discussion in the text.

Figure 4. Excerpt from Figure 4 of Clarke et al. (2014) showing a subset (rendered here as a vertical seismic section oriented west-east) of the results of the 3-D seismic reflection survey that was undertaken in 2012 in the vicinity of the Preese Hall-1 well. See Fig. 1 for presumed location (I have assumed that this section projects through the wellhead, which is implied but not clearly stated by Clarke et al., 2014); see Clarke et al. (2014) for a summary of the data processing methodology. The section has been ornamented consistent with Fig. 2(a), using data from de Pater and Baisch (2011). The labelling is from the original Figure by Clarke et al. (2014), so cannot be removed; it evidently obscures much detail. Depths of well perforations for fracking stage 2 are quoted both as Measured Depth (MD) and as True Vertical Depth (TVD), and are consistent with the schematic depiction in Fig. 
2. Also depicted are the Clarke et al. (2014) hypocentre (open semicircle) and what they described as a 'simplified' depiction of their inferred seismogenic fault plane, although it is unclear why this has a $\sim 45^{\circ}$ dip when their text reported the fault plane as much steeper. It is also noteworthy that some seismic reflectors are continuous across this interpreted fault, calling into question whether a fault is indeed present throughout the localities depicted. Furthermore, it is apparent from this ornamented version of this diagram that the Hodder Mudstone Formation thins abruptly towards the PreeseHall-1 well from the east. Weak zones sub-parallel to the bedding of the Hodder Mudstone were recognized in the Preese Hall-1 dataset by de Pater and Baisch (2011) and Harper (2011) and might well have accommodated the observed local thinning of this formation by bedding plane slip. Harper (2011) indeed noted that these weak zones make the mechanical properties of this formation anisotropic. The Preese Hall-1 wellbore also experienced deformation within the Hodder Mudstone; caliper tool measurements reported by de Pater and Baisch (2011) indicate that this deformation was concentrated between depths (MD) of 8502 and $8626 \mathrm{ft}$ or $2590-2636 \mathrm{~m}$, which correspond to 2555-2591 m TVD. This deformed interval is identified here as a white band on the well track. The effect of these details on the mechanics of the induced seismicity is a worthy target of future research, but beyond the scope of the present study. It is unfortunate that the excessive ornament applied by Clarke et al. (2014) obliterates illustration of the Hodder Mudstone Formation west of the Preese Hall-1 well, preventing further detail from being established at this stage. In my view a case can be made that a fault, steeper than that drawn by Clarke et al. (2014), is present in the vicinity of their giant arrowhead symbol, where a reflector in the Clitheroe Limestone appears offset and warped. A pointer has been added in the margin of the figure to help identify this position (located $\sim 100 \mathrm{~m}$ east of the deepest part of the Preese Hall-1 well, centred circa $2740 \mathrm{~m}$ depth) without obliterating even more of the diagram with ornament. The possibility that this fault is steep in the Clitheroe Limestone, flattens upward in the Hodder Mudstone (its past low-angle displacement causing the fabric within this shale and its coseismic slip in 2011 causing the wellbore deformation that were mentioned above) in accordance with standard theory for 'stress refraction' (e.g., Bradshaw and Zoback, 1988), then steepens upward in the overlying Pendleside Limestone (possibly coinciding in this formation with 'fault 3 ' in Fig. 3 ), is indeed worth more detailed consideration in future analysis, but this will require as a starting point a version of this diagram without the present obliteration by unnecessary labelling and with no uncertainty regarding precise location. 
Figure 5. Preferred focal mechanism for the 2 August 2011 earthquake (strike $030^{\circ}$, dip $75^{\circ}$, rake $-20^{\circ}, \mathrm{P}$-axis azimuth $347^{\circ}$ with plunge $25^{\circ}$, and T-axis azimuth $087^{\circ}$ with plunge $3^{\circ}$ ). All diagrams are equal area projections of the lower focal hemisphere, with compressional quadrants (for Pwaves) and positive-polarity quadrants (for S-waves) shaded. Ray paths to local stations, which pass upwards through the focal sphere, have been projected in the opposite direction into the lower focal hemisphere. (a) P-wave radiation pattern showing stations marked to indicate no clear polarity picks, although the first motions appear dilatational at HHF and AVH and compressional at PRH (see the online supplement). (b) Corresponding SH-wave radiation pattern. (c) Corresponding SV-wave radiation pattern. Solid and open symbols in (b) and (c) denote signals of positive and negative polarity; cross in (b) denotes an unclear (? nodal) signal. 
Figure 6. Simple conceptual model for the state of stress in relation to Preese Hall induced seismicity. This modified Mohr circle construction plots shear stress $\tau$ against normal stress $\sigma_{\mathrm{n}}$ to illustrate the state of stress at $2440 \mathrm{~m}$ depth in the Preese Hall-1 borehole (using data from Cuadrilla, 2014a,b; Fig. 2(b)) relative to the condition for shear failure on an optimally-oriented vertical strike-slip fault. $\sigma_{H \max }, \sigma_{H \min }$ and $\sigma_{V}$ denote the measured maximum and minimum horizontal stresses and vertical stress, measured as $73.4,43.6$ and $62.2 \mathrm{MPa}$, respectively. $\sigma_{\text {mean }}$ is the mean of $\sigma_{\mathrm{H} \max }$ and $\sigma_{\mathrm{H} \text { min }}$, which is $58.5 \mathrm{MPa} ; \mathrm{p}_{\mathrm{L}}$ is the lithostatic pressure, calculated from the definition as $\left(\sigma_{\mathrm{H} \text { max }}+\sigma_{\mathrm{H} \text { min }}+\sigma_{\mathrm{V}}\right) / 3$, which is $59.7 \mathrm{MPa}$; and $\mathrm{p}_{\mathrm{H}}$ is the hydrostatic pressure, calculated as the density of water $\left(1000 \mathrm{~kg} \mathrm{~m}^{-3}\right) \times$ the acceleration due to gravity $\left(9.81 \mathrm{~m} \mathrm{~s}^{-2}\right) \times$ the depth, which is 23.9 MPa. Dashed sloping line illustrates the frictional condition for fault slip, for a fault with a coefficient of friction of 0.6 . This line does not intersect the Mohr circle, indicating that under hydrostatic conditions the fault is stable. The minimum value of the bottom-hole pressure of fracking fluid, $p_{B}$, that can initiate development of induced fractures will equal $\sigma_{H \text { min }}$ (e.g., Fisher and Warpinski, 2012). The bold sloping line is constructed assuming the same coefficient of friction but that leakage of fracking fluid raises its pressure within a fault above $p_{H}$ by $15 \%$ of the difference between $p_{H}$ and $p_{L}$, or to $p_{F}=29.3 \mathrm{MPa}$, This line now touches the Mohr circle, indicating that the fault is now frictionally unstable and can thus slip in an induced earthquake. The optimum fault orientation to which this calculation applies would involve strike at $45^{\circ}$ to both horizontal principal stresses, i.e., at azimuth $052^{\circ}$ for left-lateral slip or $322^{\circ}$ for right-lateral slip on vertical faults (cf. Table 3). Corresponding calculations for non-optimally-oriented faults (such as for reactivation of a fault striking at $030^{\circ}$ and dipping at $75^{\circ}$, for slip at a rake of $-20^{\circ}$ ) are beyond the scope of the present study, but will evidently require overpressures slightly more than $15 \%$ over hydrostatic for the assumed conditions, the excess depending on the precise difference in orientation between the stress field and the fault. It is likewise apparent that variations in other parameters, such as a smaller value for the coefficient of friction or the occurrence within the fault of $15 \%$ of a higher overpressure, caused by $p_{B}$ exceeding $p_{L}$, would facilitate frictional instability on the fault; hence the importance of being able to constrain as accurately as possible each of these parameters. 


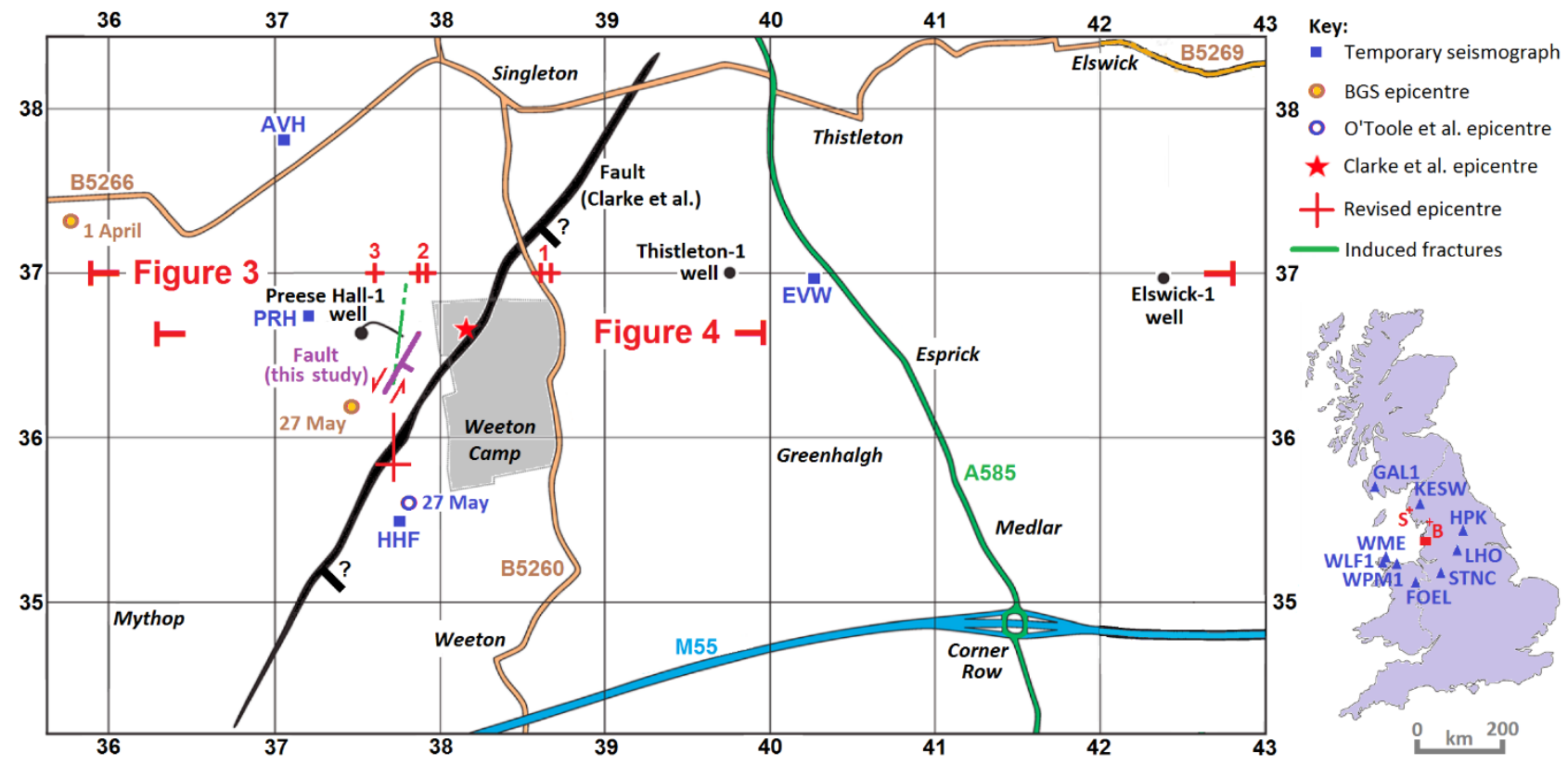

Figure 1 


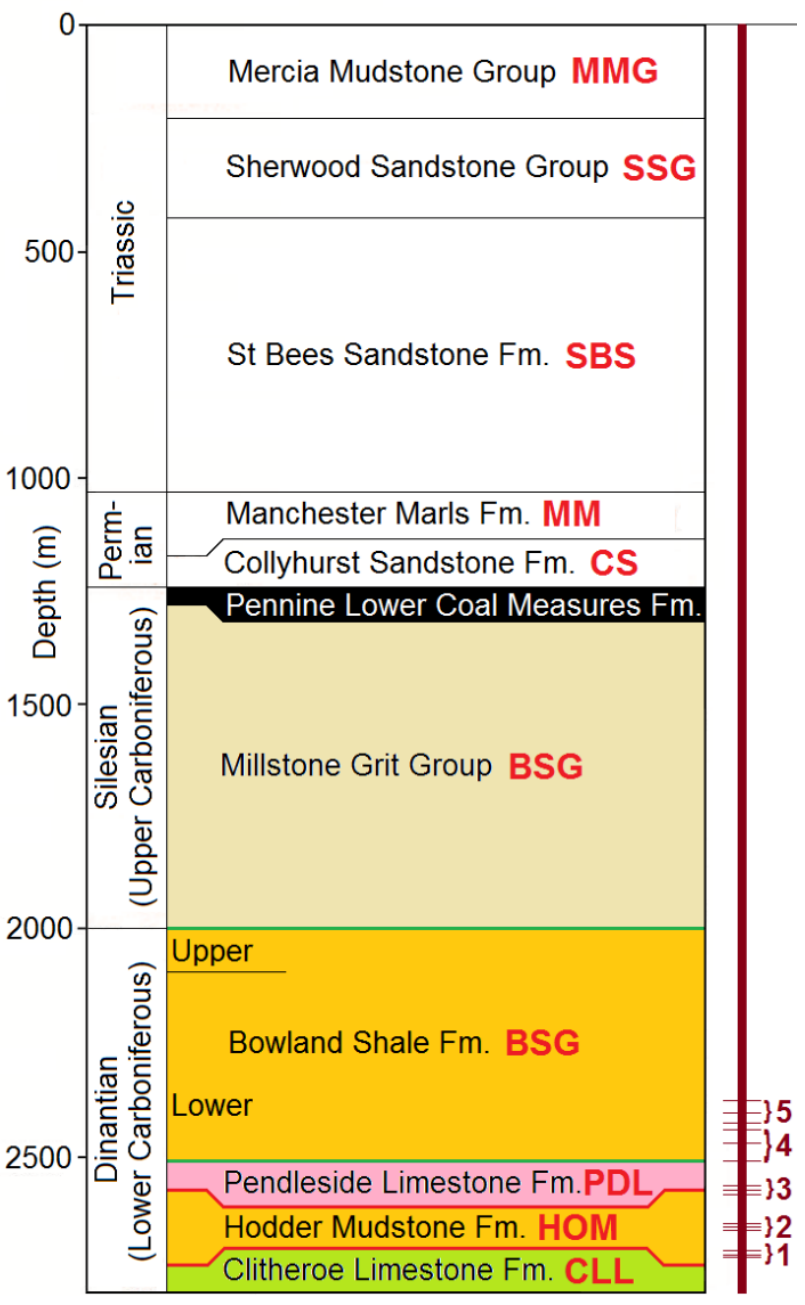

(a)

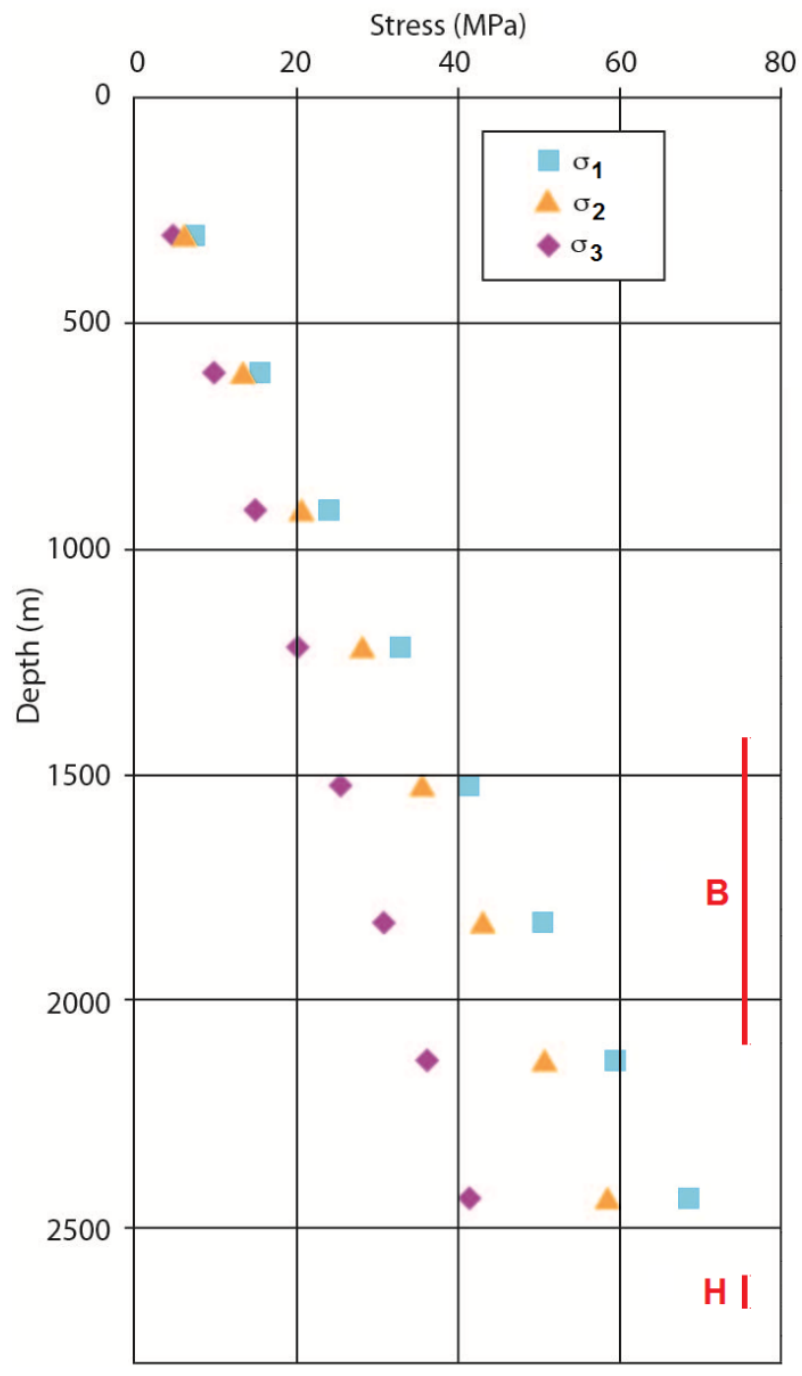

(b)

Figure 2 


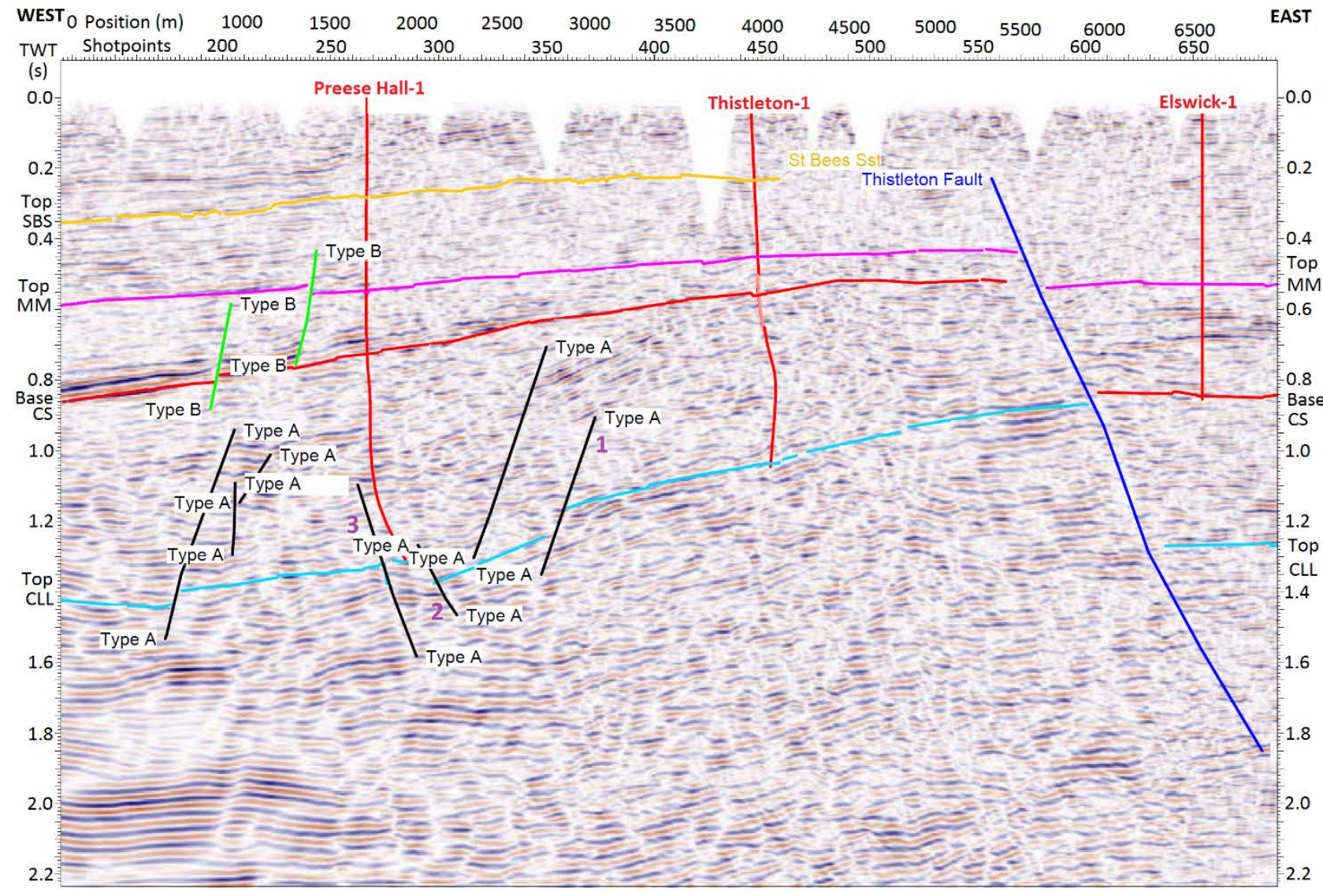

Figure 3 


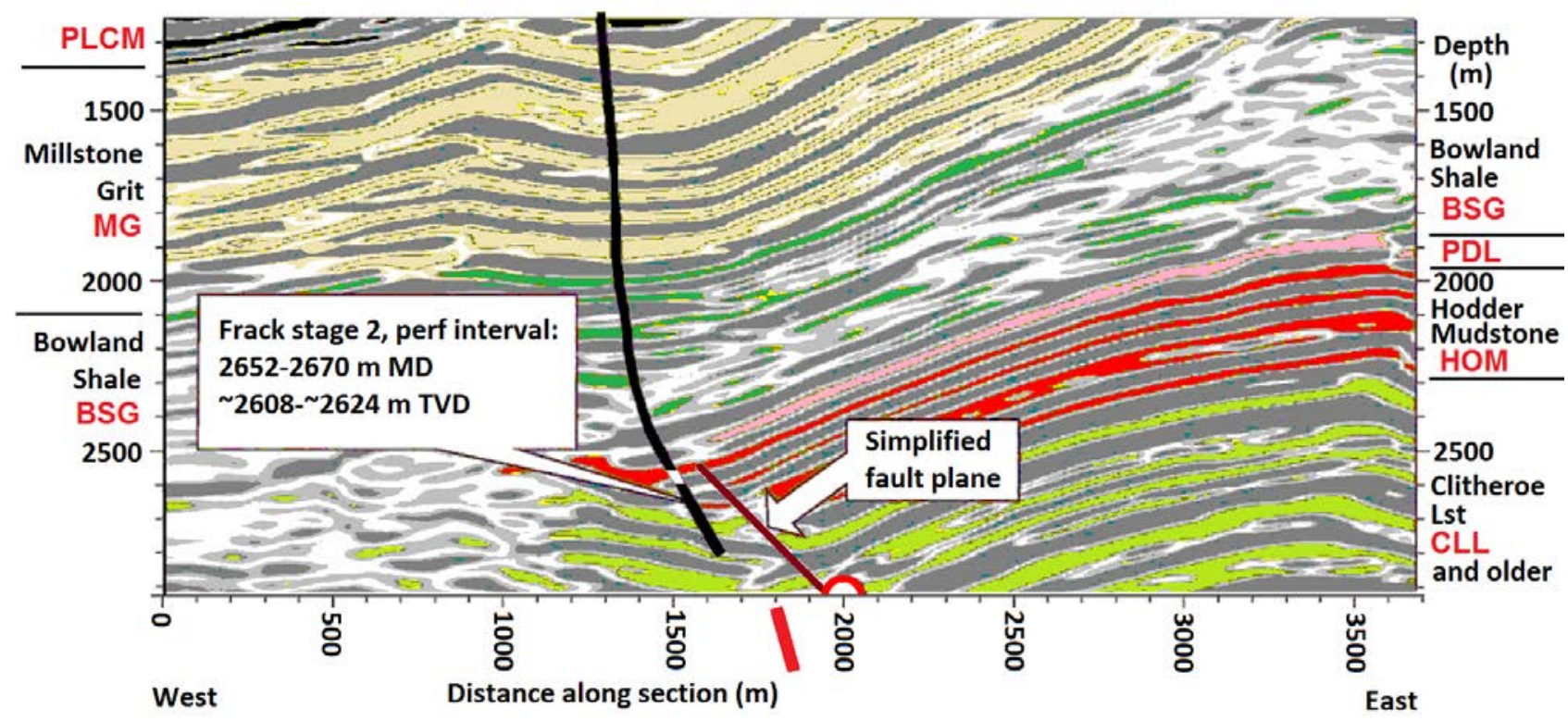

Figure 4 

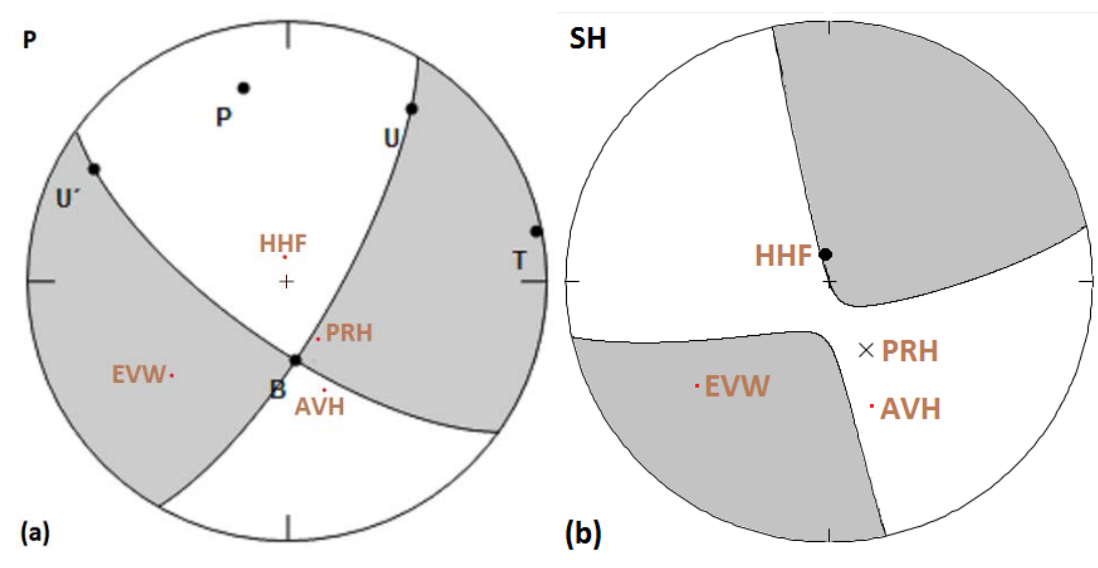

sv

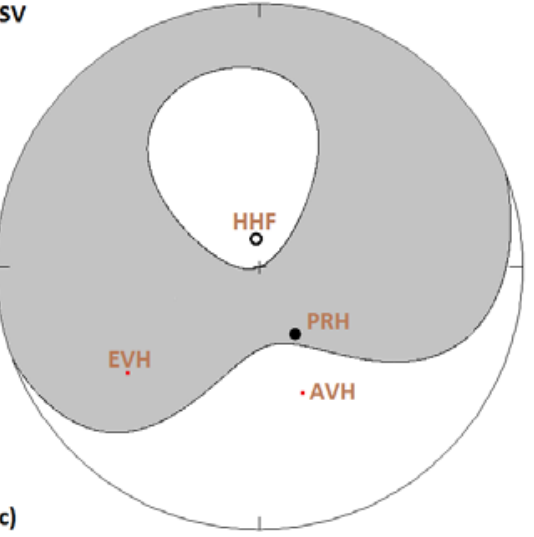

Figure 5 


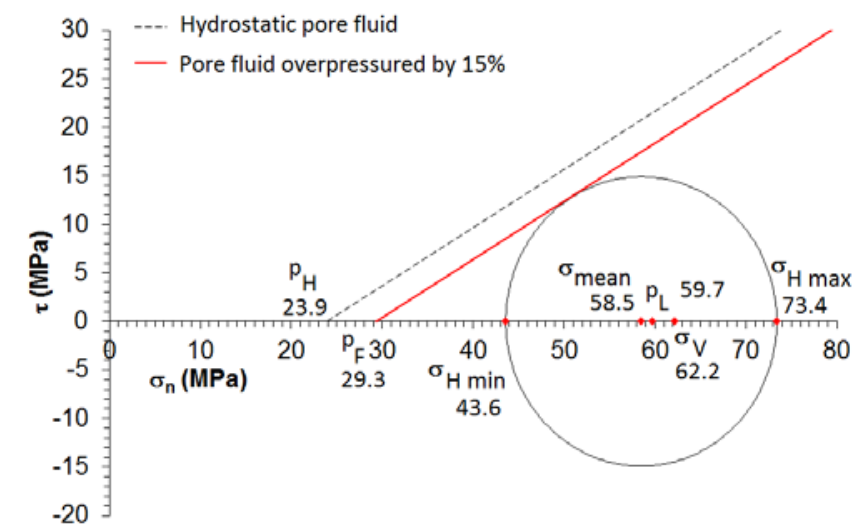

Figure 6 


\begin{tabular}{|c|c|c|c|c|c|}
\hline $\begin{array}{l}\mathrm{H} \\
(\mathrm{m})\end{array}$ & $\begin{array}{l}V_{p} \\
\left(\mathrm{~m} \mathrm{~s}^{-1}\right)\end{array}$ & $\mathrm{V}_{\mathrm{P}} / \mathrm{V}_{\mathrm{S}}$ & $\begin{array}{l}V_{S} \\
\left(\mathrm{~m} \mathrm{~s}^{-1}\right)\end{array}$ & $v$ & Stratigraphy \\
\hline 647 & 3452 & 1.99 & 1735 & 0.331 & MMG to $207 \mathrm{~m}$; SSG to $423 \mathrm{~m}$; SBS to $647 \mathrm{~m}$ \\
\hline 1394 & 4384 & 1.99 & 2203 & 0.331 & SBS to 1030 m; MM to 1170 m; CS to 1247 m; PLCM to 1279 m; MG to $1394 \mathrm{~m}$ \\
\hline 2065 & 4812 & 1.81 & 2659 & 0.280 & MG to 1993 m; BSG to 2065 m \\
\hline$\infty$ & 4000 & 1.68 & 2381 & 0.226 & BSG to $2507 \mathrm{~m}$; PDL to $2576 \mathrm{~m}$; HOM to $2744 \mathrm{~m}$; CLL to $2773 \mathrm{~m}$ (not bottomed) \\
\hline
\end{tabular}

$\mathrm{H}$ is the depth of the base of each layer; $\mathrm{V}_{\mathrm{P}}$ and $\mathrm{V}_{\mathrm{S}}$ are the $\mathrm{P}$ - and S-wave velocities, and $\mathrm{V}$ is Poisson's ratio, which relates to $V_{P} / V_{S}$ in accordance with standard theory [e.g., Westaway and Younger, 2014]. This seismic velocity model, used for earthquake location using the local seismograph stations (see the online supplement for details), is based on that from Clarke et al. [2014], except that layer 4 has been continued downward indefinitely rather than being superseded by a layer representing Lower Palaeozoic metamorphic basement at $2520 \mathrm{~m}$. Stratigraphic information is from de Pater and Baisch [2011]. Stratigraphic codes denote the following: MMG, Mercia Mudstone Group (Late Triassic); SSG, Sherwood Sandstone Group (Early Triassic); SBS, St Bees Sandstone Formation (Early Triassic); MM, Manchester Marls Formation (Late Permian); CS, Collyhurst Sandstone Formation (Early Permian), with base at the Variscan Unconformity; PLCM, Pennine Lower Coal Measures Formation (Late Carboniferous [Silesian]; Westphalian); MG, Millstone Grit Group (Late Carboniferous [Silesian]; Namurian); BSG, Bowland Shale Formation (late Early Carboniferous [Dinantian]; Viséan to Late Carboniferous [Silesian]; Namurian); PDL, Pendleside Limestone Formation (Early Carboniferous [Dinantian]; Viséan); HOM, Hodder Mudstone Formation (Early Carboniferous [Dinantian]; Viséan); and CLL, Clitheroe Limestone Formation (Early Carboniferous [Dinantian]; latest Tournaisian to earliest Viséan). These codes are searchable (at http://www.bgs.ac.uk/lexicon/lexicon.cfm) to provide additional detail. 
Table 2: Drilling induced tensile fracture data, 1

\begin{tabular}{lllll}
\hline$\alpha_{1}-\alpha_{2}\left({ }^{\circ}\right)$ & $w(\mathrm{ft})$ & $\alpha_{M}\left(^{\circ}\right)$ & $w \times \alpha_{M}$ & $D$ \\
\hline $155-160$ & 0.765 & 157.5 & 120.536 & 252.837 \\
$160-165$ & 2.602 & 162.5 & 422.832 & 451.745 \\
$165-170$ & 9.643 & 167.5 & 1615.179 & 644.624 \\
$170-175$ & 11.480 & 172.5 & 1980.230 & 115.807 \\
$175-180$ & 28.776 & 177.5 & 5107.653 & 95.717 \\
$180-185$ & 2.755 & 182.5 & 502.806 & 128.290 \\
$185-190$ & 2.143 & 187.5 & 401.786 & 299.577 \\
$190-195$ & 2.755 & 192.5 & 530.357 & 779.807 \\
$200-205$ & 0.765 & 202.5 & 154.974 & 550.651 \\
& ----- & & ----- & ---- \\
Sum & 61.684 & & 10836.352 & 3319.055
\end{tabular}

This table presents an analysis of the dataset of drilling-induced tensile fractures depicted in Fig. 6 of Baker Hughes (2011). The data thus depicted consist of lengths (w) of drilling induced tensile fractures, grouped by $5^{\circ}$ ranges of azimuth $\left(\alpha_{1}-\alpha_{2}\right)$, observed in the Preese Hall-1 borehole between depths of 4650 and $6869 \mathrm{ft}$ or 1417 and $2094 \mathrm{~m}$. The mid-point of each of these ranges of azimuth is denoted by $\alpha_{M}$. The mean azimuth of this sample of drilling induced tensile fractures is determined, as standard, as the sum of $\left(\mathrm{w} \times \alpha_{\mathrm{M}}\right)$ divided by the sum of $\mathrm{w}$ and is $175.7^{\circ}$. $\mathrm{D}$ is the weighted squared deviation for the data in each azimuth range, calculated as standard from the mean value and the values of $w$ and $\alpha_{M}$. The sample variance is determined, as standard, from the sum of $D$ and the sum of $w$ and is $60.53^{\circ 2}$, making the sample standard deviation $7.8^{\circ}$ and thus giving $5.2^{\circ}$ as twice the standard error in the mean value. These values are similar to those obtained by Baker Hughes (2011), who reported the mean as $173.6^{\circ}$ and the sample standard deviation as $7.6^{\circ}$, which they rounded for some reason as $173 \pm 10^{\circ}$; the difference between my results and theirs may be because they used the raw (ungrouped) dataset to which I have not had access. 
Table 3: Drilling induced tensile fracture data, 2

\begin{tabular}{llll}
$\begin{array}{l}\text { Depth } \\
-\end{array}$ & & & \\
$(\mathrm{ft})$ & $(\mathrm{m})$ & $\alpha\left(^{\circ}\right)$ & $\mathrm{D}$ \\
\hline 8553 & 2607 & 186.8 & 0.18 \\
8572 & 2613 & 195.6 & 70.42 \\
8612 & 2625 & 179.5 & 58.73 \\
8638 & 2633 & 185.2 & 4.04 \\
8642 & 2634 & 186.8 & 0.18 \\
8646 & 2635 & 188.1 & 0.86 \\
8650 & 2637 & 191.3 & 16.77 \\
8656 & 2638 & 189.0 & 3.36 \\
8788 & 2679 & 182.5 & 22.31 \\
& & ---1 & -- \\
Sum & & 1684.9 & 176.87 \\
--
\end{tabular}

This table presents an analysis of the dataset of drilling-induced tensile fractures depicted in Fig. 4.2 of Harper (2011). The data thus depicted consist of measurements of the azimuth $(\alpha)$ of individual fractures, observed in the Preese Hall-1 borehole between depths of 8450 and $8800 \mathrm{ft}$ or 2576 and $2682 \mathrm{~m}$. The mean azimuth of this sample of fractures is determined, as standard, as the sum of $\alpha$ divided by the number of measurements, and is $187.2^{\circ}$. D denotes the squared deviation of each measurement from this mean value. The sample variance is determined, as standard, from the sum of $D$ and the number of measurements, and is $22.11^{\circ 2}$, making the sample standard deviation $4.7^{\circ}$ and thus giving $3.1^{\circ}$ for twice the standard error in the mean value. 